Article

\title{
Overcoming Immunological Resistance Enhances the Efficacy of a Novel Anti-tMUC1-CAR T Cell Treatment against Pancreatic Ductal Adenocarcinoma
}

\author{
Mahboubeh Yazdanifar ${ }^{1}{ }^{1}$, Ru Zhou ${ }^{1}$, Priyanka Grover ${ }^{1}$, Chandra Williams ${ }^{1}$, Mukulika Bose ${ }^{1}$, \\ Laura J. Moore ${ }^{1}$, Shu-ta Wu ${ }^{1}$, John Maher ${ }^{2}$, Didier Dreau ${ }^{1} \mathbb{D}$ and Pinku Mukherjee ${ }^{1, *}$ \\ 1 Department of Biological Sciences, University of North Carolina at Charlotte, 9201 University City \\ Boulevard, Charlotte, NC 28223, USA; myazdani@uncc.edu (M.Y.); rzhou@uncc.edu (R.Z.); \\ pgrover@uncc.edu (P.G.); cwill297@uncc.edu (C.W.); mbose@uncc.edu (M.B.); \\ laura.j.moore@uncc.edu (L.J.M.); swu18@uncc.edu (S.-t.W.); ddreau@uncc.edu (D.D.) \\ 2 King's College London, School of Cancer and Pharmaceutical Sciences, Guy's Hospital Campus, Great Maze \\ Pond, London SE1 9RT, UK; john.maher@kcl.ac.uk \\ * Correspondence: pmukherj@uncc.edu
}

Received: 21 August 2019; Accepted: 9 September 2019; Published: 11 September 2019

\begin{abstract}
Chimeric antigen receptor (CAR) $\mathrm{T}$ cells have shown remarkable success in treating hematologic cancers. However, this efficacy has yet to translate to treatment in solid tumors. Pancreatic ductal adenocarcinoma (PDA) is a fatal malignancy with poor prognosis and limited treatment options. We have developed a second generation CAR T cell using the variable fragments of a novel monoclonal antibody, TAB004, which specifically binds the tumor-associated-MUC1 (tMUC1). tMUC1 is overexpressed on $\sim 85 \%$ of all human PDA. We present data showing that TAB004-derived CAR T cells specifically bind to tMUC1 on PDA cells and show robust killing activity; however, they do not bind or kill normal epithelial cells. We further demonstrated that the tMUC1-CAR T cells control the growth of orthotopic pancreatic tumors in vivo. We witnessed that some PDA cells (HPAFII and CFPAC) were refractory to CAR T cell treatment. qPCR analysis of several genes revealed overexpression of indoleamine 2, 3-dioxygenases-1 (IDO1), cyclooxygenase 1 and 2 (COX1/2), and galectin-9 (Gal-9) in resistant PDA cells. We showed that combination of CAR T cells and biological inhibitors of IDO1, COX1/2, and Gal-9 resulted in significant enhancement of CAR T cell cytotoxicity against PDA cells. Overcoming PDA resistance is a significant advancement in the field.
\end{abstract}

Keywords: Immunotherapy; targeted therapy; pancreatic cancer; pancreatic ductal adenocarcinoma; CAR T cell; engineered T cell; MUC1; resistance

\section{Introduction}

Pancreatic ductal adenocarcinoma (PDA), which arises from exocrine cells of the pancreas [1], is one of the deadliest forms of cancer with a mortality rate closely parallel to incidence [2]. It is the third leading cause of cancer related deaths in the United States, yet treatment options are limited and often associated with a high recurrence rate and poor prognosis [3]. PDA, once diagnosed, is already resistant or soon becomes resistant to conventional therapies [4]. Thus, developing new strategies targeting resistant PDA is warranted.

Chimeric antigen receptor T cell (CAR T cell) therapy is an exciting approach that arms $\mathrm{T}$ cells with a chimeric receptor that can recognize a surface antigen on tumor cells [5]. CAR T cell therapy has shown enormous success in treating hematologic malignancies [6,7] and metastatic melanoma [8]; however, this success has not been extended to adenocarcinomas [9]. This may be due to the limited selection of antigens that are expressed at a high level on the surface of solid tumors. 
MUC1, a transmembrane glycoprotein expressed at the apical surface of epithelial cells [10], is recognized as the second most targetable antigen by the national cancer institute [10]. The aberrant tumor-associated form of MUC1 (tMUC1) is predominantly expressed in $>80 \%$ of human PDA $[11,12]$ and is a key modulator of several signaling pathways that affect oncogenesis, motility, and metastasis. tMUC1 overexpression occurs at the early stages of the disease [13] and high expression is associated with poor prognosis in PDA patients [14].

Few studies have tested CAR T cell therapy in PDA targeting antigens, such as mesothelin [15], NY-ESO-1 (NCT01967823), and ROR1 [16]. MUC1 has also been targeted in CAR T cell settings by our collaborators $[17,18]$ and two other groups [19] and shown promising results, but needs further validation. Most of CAR T cell clinical trials on PDA have targeted mesothelin, which is also expressed on the normal mesothelial cells. There is only one clinical trial investigating an anti-tMUC1 CAR $\mathrm{T}$ cell for treating patients with MUC1 positive advanced refractory solid tumors including PDA (NCT02587689) [20]. The result of this trial shows adverse reactions in patients. This may be due to using scFv from an anti-tMUC1 antibody $(\mathrm{Ab})$ that also reacts with normal MUC1 expressed on normal cells.

In this study, we introduce a novel anti-tMUC1-CAR $\mathrm{T}$ cell using $\mathrm{scFv}$ derived from a highly specific anti-tMUC1 monoclonal Ab, TAB004, that does not recognize the normal form of MUC1 [21,22]. TAB004 detects tMUC1 on tissues of PDA and breast cancer patients, on PDA cells, and PDA stem cells, but spares recognition of normal epithelial cells [23-25]. Previously, we have shown specific localization of TAB004 in breast and pancreatic tumors in human MUC1 transgenic mouse models in which the entire glandular epithelia express normal human MUC1, further validating the tumor-specificity of TAB004 $[22,26,27]$. This specificity is critical, since targeting shared antigen by CAR T cells may cause fatal toxicity [28]. We tested the engineered tMUC1-CAR T cell against a panel of human PDA cell lines with varying expression levels of tMUC1, as well as against normal epithelial cells and fibroblasts.

PDA is an immunologically cold tumor with known resistance to a variety of therapies, including immunotherapy [29]. Thus, it was not surprising that we found that some of the PDA cells were refractory to tMUC1-CAR T cell treatment. Gene expression profile of resistant vs. sensitive PDA cells revealed the overexpression of several genes associated with immune tolerance such as indoleamine 2 , 3-dioxygenases-1 (IDO1), cyclooxygenase 1 and 2 (COX1/2), adenosine deaminases acting on RNA (ADAR1), and galectin-9 (Gal-9). Thus, we hypothesized that blocking the above proteins can overcome the immune tolerance of resistant PDA cells to tMUC1-CAR T cell therapy. We present data indicating that combination therapy of tMUC1-CAR T cells with biological inhibitors of resistance inducing genes resulted in significant enhancement of tMUC1-CAR T cell cytotoxicity against resistant PDA cells. These novel combinations may have major clinical significance in designing future CAR T cell therapies against resistant PDA.

\section{Materials and Methods}

\subsection{Cells}

All the PDA cell lines used in this study were originally purchased from American type culture collection (ATCC, Manassas, VA, USA) and cultured as instructed. PDA and HPDE (normal pancreatic epithelial) cell lines were used for fewer than 15 days after resuscitation with a passage window of 1-9. Primary T cells were derived from human peripheral blood mononuclear cells (PBMCs), which were bought from STEMCELL Technologies (\#70025.1, Cambridge, MA, USA). Normal human primary fibroblasts and breast epithelial cells were obtained from Coriell Institute (Camden, NJ, USA) and used within 1-3 passages after resuscitation. Fibroblasts were originally derived from biopsies of lung, skin, and endometrium of healthy individuals. The BxPC3-MUC1 cell line was made by retroviral transfection of BxPC3 wild type (ATCC) with the PLNCX.1 plasmid (K1060-C, Mayo Clinic, Rochester, MN, USA), which contains the full-length human MUC1 gene. BxPC3-Neo was transfected with the empty PLNCX.1 plasmid containing neomycin resistance gene. The MiaPaCa2-Luc cell line was 
generated by Lipofectamine transfection (\#L3000015, Lipofectamine 3000, Invitrogen, Carlsbad, CA, USA) of the MiaPaCa2 cell line with pGL4.50[luc2/CMV/Hygro] vector (Promega, Madison, WI, USA). More detailed information regarding the origin, source, and culture condition of the cells used in this study is provided in Supplementary Data Table S1.

\subsection{CAR Constructs and Cloning}

A second generation anti-tMUC1 CAR harboring TAB004 Ab scFv was synthesized by subcloning the scFv from TAB004 [21] into the SFG-based retroviral backbone plasmid encoding the transmembrane and intracellular domains of CD28 and CD3 $\zeta$ (synthesized by Dr. John Maher's group [30]). This CAR contains a myc tag for detection. The CAR-mKate construct was made by cloning PCR-amplified tMUC1-CAR sequence into the PLNCX.1 retroviral vector (K1060-C, Mayo Clinic) at the MluI site along with the mKate2 sequence fused through a GA linker. The mKate2 gene (pFA6a-mkate-kanmx6) was a gift from Dr. Richard Chi. CTL-CAR ( $2^{\text {nd }}$ generation CAR missing the scFv domain) was created by PCR cloning of CAR in three fragments missing the majority of the TAB scFv sequence. All cloning was done using NEBuilder ${ }^{\circledR}$ HiFi DNA Assembly Cloning Kit (\#E5520, NEB, Ipswich, MA, USA). PCRs were done using Q5 ${ }^{\circledR}$ High-Fidelity DNA Polymerase (\#M0491, NEB).

\subsection{Viral Transfection of $T$ Cells}

Retroviruses were generated by transduction of GP2-293 packaging cell line with $10 \mu \mathrm{g}$ CAR DNA and pVSV envelope plasmid. Viral supernatant ( $48 \mathrm{~h}$ post transduction) was used to infect T cells. Human PBMCs were activated by CD3/CD28 Dynabeads (\#111.61D, Thermo Fisher, Waltham, MA, USA) 3 days prior to infection. Non-tissue culture plates (\#351146, Corning Inc., Corning, NY, USA) were coated with retronectin $(1 \mathrm{mg} / \mathrm{mL})$ (Takara, Mountain View, CA, USA) and incubated at $4{ }^{\circ} \mathrm{C}$ at least $12 \mathrm{~h}$ before infection. The following day, retronectin was removed and the plates were blocked with $2 \%$ BSA for $30 \mathrm{~min}$. Viral supernatant was added to retronectin-coated plates, which were subsequently centrifuged at $2000 \times g$ for $2 \mathrm{~h}$ at $32^{\circ} \mathrm{C}$. Viral supernatants were removed, and activated T cells were added to the coated plates. Plates with cells were spun at $1000 \times g$, at $32{ }^{\circ} \mathrm{C}$ for $10 \mathrm{~min}$ and incubated overnight. Cultures were maintained in complete RPMI-1640 with 200-300 U/mL human recombinant IL-2 (\#200-02, PeproTech, Rocky Hill, NJ, USA) and the media was refreshed every 3 days. To avoid T cell exhaustion, from day 10 onward, cultures were maintained at $50 \mathrm{U} / \mathrm{mL}$ IL-7 and IL-15 (\#200-07, PeproTech). T cells that had been activated but not transduced were used as mock T control. CAR expression level was characterized by flow cytometry using anti-myc tag $\mathrm{Ab}$, and $\mathrm{T}$ cells were used between days 11 to 14 days post infection. CAR positive $T$ cells were not sorted and the mixed population of transduced T cells with $\sim 40 \%$ CAR T cells were used in all assays.

\subsection{T Cell Cytotoxicity}

To test $\mathrm{T}$ cell cytotoxicity against target cells, 5000-10,000 cancer cells or normal cells were plated in triplicate in 96 well plates one day prior to co-culture. Mock or CAR T cells were counted and added to cancer cells at the indicated target to effector (T:E) ratio. Cell viability was evaluated by MTT assay (MTT $500 \mu \mathrm{g} / \mathrm{mL}$, Sigma, St. Louis, MO, USA) 24, 48, and $72 \mathrm{~h}$ after co-culture according to the product instructions. The OD value at $540 \mathrm{~nm}$ was read and percentage survival was calculated as $100-[$ (mock $\left.\mathrm{T}_{\mathrm{OD}}-\mathrm{CAR} \mathrm{T}_{\mathrm{OD}}\right) /$ mock $\left.^{\mathrm{T}} \mathrm{OD} \times 100\right]$. To measure direct cytotoxicity activity of the CAR $\mathrm{T}$ cells, a lactate dehydrogenase (LDH)-based technique, CytoTox $96{ }^{\circledR}$ Non-Radioactive Cytotoxicity Assay (Promega) was used. BxPC3-Neo and BxPC3-MUC1 cells were plated in a 96 well plate $(20,000$ cells/well) and incubated with 200,000 mock or CAR T cells (T:E 1:10) for 8, 16, and $24 \mathrm{~h}$. The amount of released LDH and subsequent cytotoxicity was measured and calculated according to the manufacturer's instructions. 


\subsection{Binding Assay}

HPAFII, a moderate-to-high MUC1-expressing PDA cell line, was plated in 6 well plates $\left(150,000\right.$ cells/well) and incubated at $37{ }^{\circ} \mathrm{C}$ overnight. Next, the cells were stained with nuclei live cell stain Hoechst (\#33342, Thermo Fisher, Waltham, MA, USA) for $30 \mathrm{~min}$ and washed 3 times. $1 \times 10^{6}$ CAR T cells or CTL T cells (both expressing CAR constructs fused to mKate fluorescent tag) were added to the respective wells and plates were incubated at $37^{\circ} \mathrm{C}$ for $4 \mathrm{~h}$ with occasional rocking. Cells were washed 2 times and imaged using the DeltaVision workstation (Applied Precision, GE, Boston, MA, USA).

\subsection{Flow Cytometry}

The CAR expression level was quantified using myc tag-FITC staining (Cell Signaling Technology, Danvers, MA, USA). T cell subtypes were determined by staining for CD4-PE/Cy7 and CD8-eF450 (BD Biosciences, San Jose, CA, USA). PD1-APC (eBioJ105), PDL1-FITC (clone MIH2), IFN- $\gamma$-APC (clone 4S.B3), and perforin-PE (clone dG9) Abs were obtained from eBioscience. The human tMUC1 expression on PDA cells was measured by staining with TAB004 primary Ab (provided by OncoTab Inc., Charlotte, NC, USA) and FITC-anti-mouse secondary Ab (\#31535, Invitrogen). Dead cells were excluded by 7-AAD staining (\#555816, BD Biosciences, Franklin Lakes, NJ, USA). Data were acquired on BD LSR Fortessa flow cytometer (BD Biosciences) and analyzed using the FlowJo software (version 8.8.7, Tree Star Inc., Ashland, OR, USA).

\subsection{ELISA}

The FBS-free supernatant of PDA cells co-cultured with T cells was assessed for released IFN- $\gamma$ and granzyme B after $72 \mathrm{~h}$ of co-culture, using the human IFN gamma ELISA Kit (88-7316-22, Life Technologies, Cambridge, MA, USA) and human Granzyme B DuoSet ELISA (DY2906-05, R\&D, Minneapolis, MN, USA). Shed MUC1 was measured using human MUC1 ELISA kit (OncoTab Inc.). All of the ELISAs were performed on the FBS-free supernatant after $72 \mathrm{~h}$ of co-culture.

\section{8. $R T-P C R, q P C R$}

RNA was extracted from cancer cells by RNeasy Plus Mini Kit (\#74134, Qiagen, Hilden, Germany). RT-PCR was performed using AccessQuick ${ }^{\text {TM }}$ RT-PCR system (\#A1700, Promega, Madison, WI, USA) and samples were run on $1.2 \%$ agarose gel. The human MUC1 primers used were Forward TGC ATC AGG CTC AGC TTC A, Reverse GAA ATG GCA CAT CAC TCA G, and Tm $60{ }^{\circ} \mathrm{C}$. qPCR primers were designed using the NCBI primer design tool and synthesized by MWG Eurofins (Louisville, KY, USA). The primer sequences will be available upon request. The relative expression levels of multiple genes such as MUC1, PD1, PDL1, LIF, VEGF, IDO1/2, COX1/2, ADAR1, TGFB, TGFBRI/II, PDGF, M6PR, Gal-9, and TRAIL were quantified in cancer cells before and after exposure to mock and CAR T cells using Applied Biosystems ${ }^{\circledR} 7500$ fast Real-Time PCR machine and SYBR Green PowerUp Master Mix (A25742, Life Technologies). Relative expression of each gene was calculated as 1/(gene CT - GAPDH CT).

\subsection{Apoptosis Assay}

Mock and CAR T cells were stained with Annexin V/Propidium iodide (PI) dyes according to the dead cell apoptosis kit protocol (V13242, Life Technologies) before and after co-culture with cancer cells for 24,48 , and $72 \mathrm{~h}$. The percentage of positive cells was assessed using flowcytometry. 


\subsection{Proliferation Assay}

HPAFII, CFPAC, and MiaPaCa2 cells were plated in 6 well plates (500,000 cells/well). The next day, mock and CAR T cells were added to the cancer cells at 1:5 T:E ratio. Number of live T cells per well were calculated at 24,48 , and $72 \mathrm{~h}$ using trypan blue $(0.4 \%$, Thermo Fisher) staining and Countess II automated cell counter (Life Technologies).

\subsection{Imaging}

$1 \times 10^{6}$ CAR T cells expressing CAR-mKate were plated in $35 \mathrm{~mm}$ Poly-d-lysine Coated MatTek dish (\#P35GCOL-0-14-C, MatTek, Ashland, MA, USA) for $24 \mathrm{~h}$. The next day, cells were stained with nuclei live cell stain, Hoechst (Thermo Fisher \#33342) for $30 \mathrm{~min}$ and washed gently once, then imaged by DeltaVision workstation (Applied Precision, GE). Image analysis was done using Softworx 6.1 (Applied Precision, GE).

Videos of CAR T cells killing BxPC3-MUC1 vs. BxPC3-Neo cells were taken by time lapse imaging using a DeltaVision OMX-SR imaging system (\#29115476, GE). Cancer cells and CAR T cells were co-cultured in $35 \mathrm{~mm}$ MatTek dish and placed in the microscope's $37^{\circ} \mathrm{C} 5 \% \mathrm{CO}_{2}$ incubator overnight. Images were taken over the course of $8 \mathrm{~h}$ at $7 \mathrm{~min}$ intervals. PI dye was added to the culture at $50 \mathrm{ng} / \mathrm{mL}$ [31]. Only apoptotic cells are susceptible to PI infusion and turn red upon absorption. Pictures were analyzed using ImageJ v1.51f program (Rasband, NIH).

\subsection{Combination Therapy with Drugs and Blocking Antibody}

To assess the effect of drugs on CAR $\mathrm{T}$ cell cytotoxicity, cancer cells were plated at 5,000/well concentration in 96 well plates in triplicate. Next day, cells were treated with drugs (1-Methyl-D-tryptophan (1-MT, \#452483, Sigma), indomethacin (\#17378, Sigma), gemcitabine hydrochloride (\#G6423, Sigma), paclitaxel (Taxol equivalent, \#P3456, Invitrogen) and 5-Fluorouracil (\#F6627, Sigma)) at indicated concentrations for $24 \mathrm{~h}$. After $24 \mathrm{~h}$, the drug was removed, cells were washed and further incubated with mock or CAR T cells at T:E ratio of 1:10 for $72 \mathrm{~h}$. Thereafter, the percentage of surviving cancer cells were measured using the MTT assay. For Gal-9 and PD-1 blocking experiments, cancer cells were plated at 10,000 cells/well concentration in 96 well plates in triplicate. After $24 \mathrm{~h}$, mock or CAR T cells were added at T:E ratio of 1:10. 0.1, 1, and $10 \mu \mathrm{g} / \mathrm{mL}$ of Gal-9 (clone 9M1-3, BioLegend, San Diego, CA, USA) or PD-1 blocking Ab (clone EH12.2H7, BioLegend) was added to the media and incubated at $37^{\circ} \mathrm{C}$ for $72 \mathrm{~h}$. Survival was measured using the MTT assay.

\subsection{Animal Study}

12 female non-obese diabetic (NOD)-SCID gamma (NOD.Cg-prkdcscidIl2rgtm1w1; NSG ${ }^{\mathrm{TM}}$, Jackson Laboratory, Bar Harbor, ME, USA) mice were anesthetized. Using aseptic techniques, an incision was made in abdominal area off midline just above the pancreas. Then, the pancreas was gently retracted and injected with $0.5 \times 10^{6} \mathrm{MiaPaCa2}$-Luc cancer cells. The abdominal incision was sutured and the skin layers were closed using surgical clips. Mice were monitored and their body weights were checked daily for a week. 7 days post-surgery, tumor presence was confirmed using in vivo imaging system (IVIS, PerkinElmer, Waltham, MA, USA). On day 8 post-surgery, when the average ROI for pancreatic tumors was $1.4 \times 10^{6}$, mice were randomized into two groups (with even distribution of tumor size) based on their baseline luminescence intensity. One group received intravenous (IV) injection of mock T $(n=6)$ and the other received tMUC1-CAR T cells $(n=6)\left(10 \times 10^{6}\right.$ per mouse). Mice were imaged weekly by IVIS using chemo-luminescence, open filter setting in Living Image 4.3 software. On day 68 post injection, mice were sacrificed and tumors were harvested and weighed. Two mice (1 per group) died of irrelevant causes before the endpoints. 
To assess $\mathrm{T}$ cell trafficking in mice after injection, mock or CAR $\mathrm{T}$ cells were labeled with Vivotrack-680 dye (PerkinElmer) according to the manufacturer's protocol. Six MiaPaCa2-Luc tumor-bearing NSG mice were injected with either $4 \times 10^{6}$ labeled CAR T or mock T cells through tail vein $(n=3)$. Mice were sacrificed $24 \mathrm{~h}$ after injection and tumors were dissected and imaged by IVIS. Images were acquired using fluorescence Vivotrack- 680 channel with excitation $=676$ and emission $=696 \mathrm{~nm}$, and analyzed using Living Image 4.3 software. All animal studies were approved by the institutional animal care and use committee of the University of North Carolina at Charlotte (IACUC protocol \#18-010, approved 12/06/2018). All the experimental procedures complied with institutional guidelines.

\subsection{Statistical Analysis}

All of the data were analyzed by Prism (version 8.0; GraphPad Software, San Diego, CA, USA) and results are presented as mean \pm SEM. Data are representative of two or more independent experiments. The statistical analysis was done using Prism software and significance was determined using unpaired Student's $t$-test, one-way or two-way ANOVA, or non-parametric Mann-Whitney $\mathrm{U}$ test where indicated $(*, p<0.05 ; * *, p<0.01 ; * * *, p<0.001)$.

\section{Results}

\subsection{CAR Architecture, CAR Expression on Engineered T Cells, and Binding of CAR T Cells to Target PDA Cells}

The architecture of CAR constructs used in this study is illustrated in Figure 1A. TAB004 Ab's variable fragments are cloned into a second generation CAR plasmid (SFG muT4 vector backbone) containing CD28 and CD3 $\zeta$ genes (tMUC1-CAR). To test specificity of the tMUC1-CAR, we generated a control CAR (CTL-CAR), in which TAB004 scFv sequence is removed. T cells expressing CTL CAR construct is referred to as CTL T. Furthermore, to visualize surface expression of CAR constructs on $\mathrm{T}$ cells, we generated mKate fluorescent-tagged CARs named CAR-mKate and CTL-mKate, in which mKate2 gene is fused to the $C$ terminus of $C D 3 \zeta$ in tMUC1-CAR and CTL-CAR respectively. We also used uninfected T cells (designated as mock T cells) as another control. The representative dot-plot graphs show $\sim 42 \%$ myc tag positive cells in both CD4+ and CD8+ human primary $\mathrm{T}$ cells by day 12 after infection (Figure 1B). CAR surface expression on T cells was visualized using DeltaVision microscopy. Bright field and florescent images of the entire population of CAR-mKate expressing cells are shown in Figure 1C (top panel). The projection image (bottom left), and a single $\mathrm{z}$ stack image (bottom right) of the CAR T cell is shown in Figure 1C (bottom panel). Cell nuclei were stained blue with live cell stain Hoechst. A distinct red ring indicates CAR expression on the cell surface and confirms even distribution of CAR across the cell membrane, with no significant irregular patch or co-localization (Figure 1C bottom right).

We have previously shown that TAB004 Ab can detect tMUC1 in $>85 \%$ of malignant PDA tissues [23]. To test binding of tMUC1-CAR T cells to PDA cells, CAR-mKate engineered T cells were co-cultured with MUC1 expressing PDA cell line (HPAFII) for $4 \mathrm{~h}$ and imaged using DeltaVision microscope. Binding to the target HPAFII cells is observed (Figure 1D); however, when CTL-mKate engineered T cells were co-cultured with the same target cells, no binding to target cells was observed (data not shown). The intense red signal observed between CAR T cell and HPAFII indicates a polarized localization of CAR molecules, suggesting a tMUC1-dependent immunological synapse (Figure 1D). 
A

B

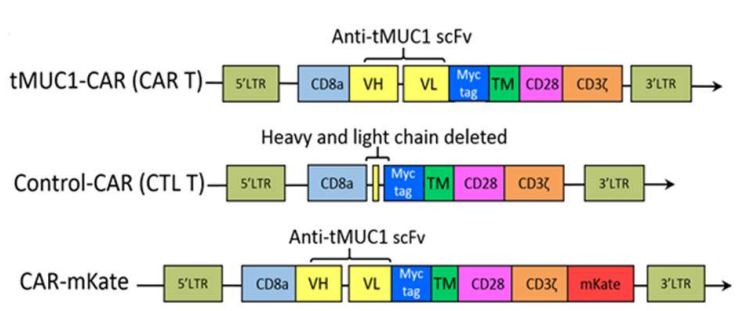

C

D

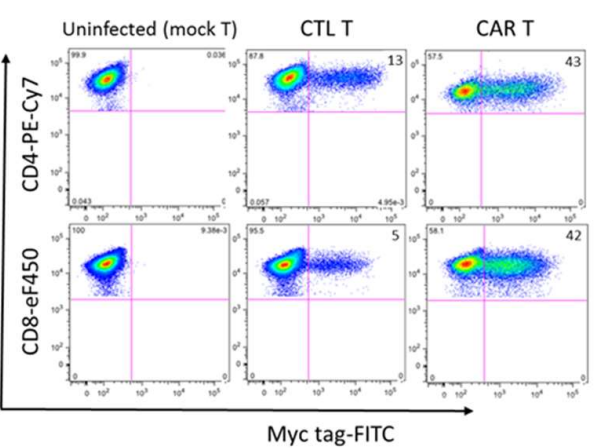

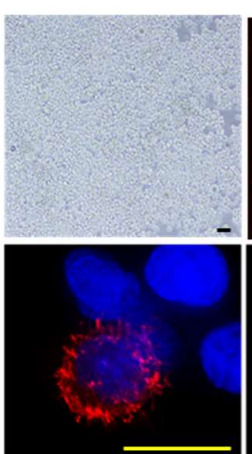

Red: CAR-mKate Blue: Nuclei

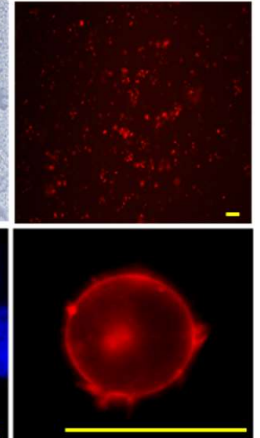

Figure 1. CAR architecture, expression on engineered T cells, and binding of CAR-T cells to targe cells. (A) The architecture of three different CAR constructs used in this study. In the original construct (tMUC1-CAR), scFv of TAB004 Ab is linked to CD28 transmembrane (TM) domain followed by CD28 and $\mathrm{CD} 3 \zeta$ intracellular domains in a retroviral plasmid. CD8a leader sequence was used as signal peptide for cell membrane expression of the CAR. In the CTL-CAR construct, scFv of TAB was removed. In the CAR-mKate construct, mKate2 gene was fused to the C-terminus of CAR flanking with a GA linker. (B) CTL-CAR and tMUC1-CAR expression measured by flow cytometry using FITC-conjugated anti-myc tag Ab, in CD4+ and CD8+ primary $\mathrm{T}$ cells on day 12 after infection. On average, $42 \%$ of T cells expressed tMUC1-CAR. (C) Bright field (top left) and fluorescent image (top right) of live T cells expressing CAR-mKate plated in $35 \mathrm{~mm}$ poly-D-lysine coated MatTek dish and imaged by DeltaVision workstation (Applied Precision, GE), projection image of a T cell expressing CAR-mKate (bottom left), and one $\mathrm{Z}$ image of the CAR-mKate $\mathrm{T}$ cell (bottom right) illustrating the ring-like structure around the cells formed by CAR-mkate expression, which indicates even distribution of CAR molecules on the T cell membrane. (D) Light and fluorescent image of CAR-mKate T cells binding to MUC1 expressing cancer cell (HPAFII). HPAFII cells were incubated with CAR-mKate T cells for $4 \mathrm{~h}$, then $\mathrm{T}$ cells were removed, HPAFII cells were washed and imaged using DeltaVision microscope. The intense red signal observed between CAR T cell and HPAFII indicates co-localization and binding of CAR molecules, which suggests the formation of immunological synapse. Nuclei were stained with Hoechst nuclei blue dye in C and D. All scale bars $=15 \mu \mathrm{m}$.

\section{2. tMUC1-CAR T Cells Show Robust Cytotoxicity against PDA Cells but not Normal Cells}

A panel of human PDA cell lines were used that expressed varying levels of MUC1. BxPC3 cells overexpressing full-length MUC1 (BxPC3-MUC1) or vector alone (BxPC3-Neo) were included to further determine if CAR T cell cytotoxicity was dependent on antigen expression. Expression level of MUC1 gene and protein was assessed using RT-PCR (Figure 2A) and flowcytometry (Figure 2B) respectively. Cells were categorized into three groups of low MUC1, moderate to high MUC1, and high MUC1 according to flowcytometry data (Figure 2B). According to RT-PCR and flowcytometry data, most PDA cell lines express some level of MUC1. Jurkat cell line was used as negative control for 
MUC1 gene expression in RT-PCR. Human pancreatic normal epithelial cell line, HPDE (H6c7), was used as a negative control in flowcytometry and cytotoxic assays. CTL T and uninfected T cells showed similar cytotoxic activity against target cells (Figure S1A); therefore, uninfected T cells (designated mock T) were used as control for all cytotoxic assays. PDA cell lines were incubated with CAR T or mock $\mathrm{T}$ cells for 24,48 , and $72 \mathrm{~h}$ at different target:effector (T:E) ratios and survival of target cells was measured using MTT assay. Percent survival was normalized to mock T cells and calculated as $100-\left[\left(\right.\right.$ mock $\left.T_{O D}-C A R T_{O D}\right) /$ mock $\left.T_{O D} \times 100\right]$. Figure $2 C$ shows the percentage of surviving target cells $72 \mathrm{~h}$ post $\mathrm{T}$ cell treatment at T:E ratio of 1:10. The majority of the tested PDA cells were efficiently killed by CAR T cells, especially the high MUC1 and moderate to high tMUC1-expressing cells (80-95\% killing), except for HPAFII and CFPAC ( 20\% and 50\% killing). Interestingly, one of the low tMUC1-expressing cell line, Capan-1, also responded well to CAR T cell cytolysis. The normal pancreatic cell line, HPDE, showed 100\% survival post co-culture with CAR T cells.

The sensitivity of the PDA cells to CAR T cell killing cannot be accurately compared between the different cell lines, since each cell line has distinct genetic makeup, which endows them with different intrinsic resistance levels. To investigate this, we used BxPC3-MUC1 and BxPC3-Neo cells, which are identical in all aspects except for their MUC1 level. As shown in Figure 2C-E, BxPC3-MUC1 cells are significantly more sensitive to CAR T cell killing compared to BxPC3-Neo cells. At a T:E ratio of 1:10 (Figure 2C), 100\% of BxPC3-MUC1 cells were killed by CAR T cell treatment, while $\sim 50 \%$ of BxPC3-Neo cells are killed. This 50\% killing with a high T:E ratio (1:10) in BxPC3-Neo cells was possibly because of the existing endogenous MUC1 expression in these cells (Figure 2A,B). However, the killing effect was completely negated when T:E ratio was lowered to 1:5 (Figure 2D). The cell survival data was further confirmed using a different cell cytoxicity assay (CytoTox $96^{\circledR}$ non-radioactive cytotoxicity assay). Percent cytotoxicity of CAR T cells/mock T cells show significantly higher amount for BxPC3-MUC1 vs. BxPC3-Neo cells (Figure 2E). Taken together, results clearly suggest a critical correlation between antigen expression levels and efficacy of CAR T cells. Next, we evaluated whether the efficacy of CAR T cell killing is dose dependent. Indeed, an increasing ratio of CAR T cells to target PDA cells resulted in dose dependent killing of the target cells (Figure 2F). CAR T cells had no effect on normal pancreatic epithelia cells (HPDE) at 1:5, 1:10, or 1:20 T:E ratio, while the same CAR T cell effectively killed the high-MUC1 expressing PDA cell lines, at all T:E ratios (Figure 2F).

Lastly, we tested if tMUC1-CAR T cells kill other normal epithelial cells or fibroblasts. We performed the same cell survival assay using eight different primary cells as targets (granted from Coriell institute) at a 1:10 T:E ratio and $72 \mathrm{~h}$ incubation with CAR T cells. Three fibroblasts from three different tissue origins and five breast epithelial cells (from mammoplasty) derived from different healthy donors were tested. All normal cells showed $100 \%$ survival when exposed to CAR T cells for $72 \mathrm{~h}$ (Figure 2G). These data suggest that the tMUC1-CAR T cells are non-toxic toward normal cells while robustly killing most PDA cell lines. This is of utmost importance, since CAR T cell toxicity in patients with epithelial tumors has raised major concerns. This data was expected, as our previous experiments including staining the PDA tissues with TAB004 Ab resulted in selective epithelial detection of tMUC1 and not the healthy adjacent stromal cells (Figure S5A).

Interaction of CAR T cells with BxPC3-MUC1 and BxPC3-Neo cells were recorded overnight using GE DeltaVision OMX-SR microscope and the videos were created using the ImageJ program. BxPC3-MUC1 cells were attacked and killed by CAR T cells in 8/11 spots, while only 3/11 spots showed killing in BxPC3-Neo plate. Red staining is indicative of dead cells that have absorbed propidium iodide dye present in the media. Videos are available as supplementary data: Video. 


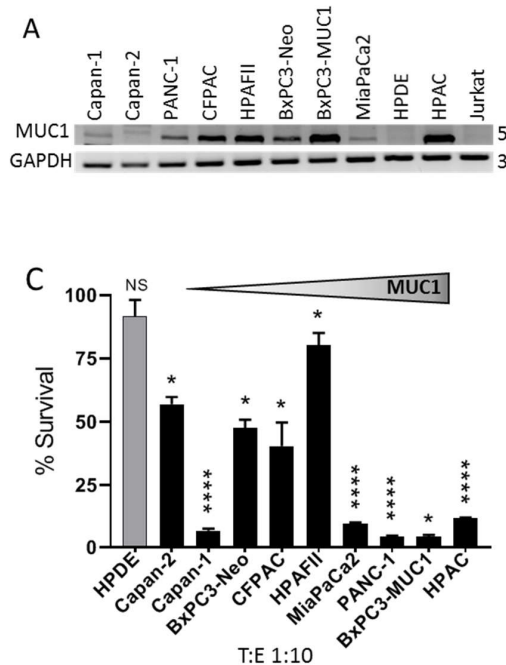

B

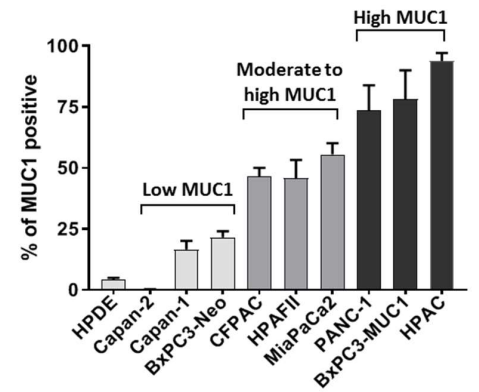

D

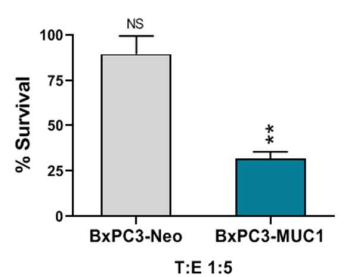

E

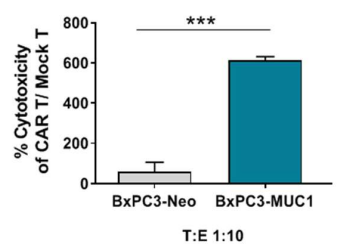

G

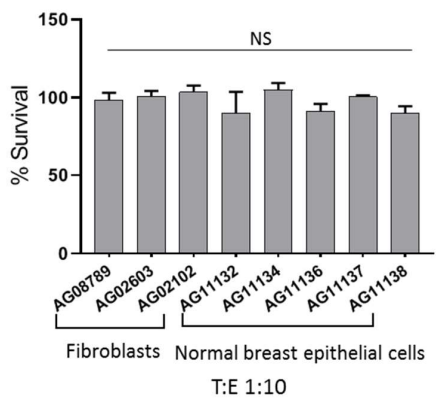

F

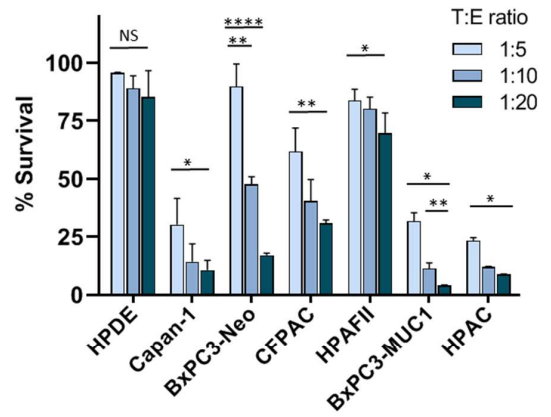

Figure 2. tMUC1-CAR T cells show robust cytotoxicity against PDA cells but not normal cells. (A) mRNA levels of human MUC1 in a panel of PDA cell lines acquired by RT-PCR. Jurkat cell mRNA was used as negative control. (B) Surface MUC1 expression in a panel of PDA cell lines detected by TAB004 Ab staining and flow cytometry. Cancer cells were categorized into three groups according to their MUC1 level. (C) Percentage survival of nine PDA cell lines when treated with CAR T cells measured by MTT assay. Percentage survival of cancer cells treated with CAR T cell was normalized to the mock T cell (uninfected). Cancer cells are ordered from low to high MUC1 (left to right). HPDE cell was used as normal control cell line. All PDA cells show a significant reduction in survival after treatment with CAR T cells. T:E ratio of 1:10 and $72 \mathrm{~h}$ incubation was applied to all cell lines. (D) The percentage survival of BxPC3-Neo and BxPC3-MUC1 treated with CAR T cells for $72 \mathrm{~h}$ at T:E ratio of 1:5. BxPC3-Neo stays intact when treated with low dose of CAR T cells (T:E 1:5), while BxPC3-MUC1 is effectively killed. (E) Spontaneous killing of BxPC3 cells by CAR T cells within $24 \mathrm{~h}$ measured by an LDH-based technique, Cytotox assay. CAR T cells show significantly higher levels of cytotoxicity against BxPC3-MUC1 cells compared to BxPC3-Neo cells. (F) The percentage survival of PDA cells and normal pancreatic epithelial cell line (HPDE) when treated with increasing doses of CAR T cells. Data shows that CAR T cell killing is dose dependent. By increasing the dose of CAR T cells, more killing was observed in PDA cells, while the survival of normal cell (HPDE), even at T:E of 1:20, remained unchanged. (G) The percentage survival of a panel of human normal primary cells, including fibroblasts and breast epithelial cells, obtained from healthy donors treated with CAR T cells for $72 \mathrm{~h}$ at T:E 1:10. There is no significant reduction in the survival level of normal primary cells when treated by CAR T cells. All data presented was normalized to mock T cell. Two-way ANOVA-multiple comparisons and Student's $t$-test were performed for determining significance. Error bars, SEM. $n=4 .{ }^{*} p<0.05$, ${ }^{* *} p<0.01,{ }^{* * *} p<0.001,{ }^{* * * *} p<0.0001$. 


\section{3. tMUC1-CAR T Cells Produce IFN- $\gamma$ and Granzyme B upon Activation and Antigen Recognition}

To determine the mechanism of $\mathrm{T}$ cell activation and function, $\mathrm{T}$ cells were co-cultured with target cells for $72 \mathrm{~h}$ and supernatants were tested for IFN- $\gamma$ and granzyme B production by specific ELISAs (Figure $3 \mathrm{~A}, \mathrm{~B}$ ). In addition, intracellular production of IFN- $\gamma$ by T cells after co-culture was measured by flowcytometry (Figure S1B). Results show that even before exposure to cancer cells, activated T cells produced some level of IFN- $\gamma$ cytokine (intracellular and released); however, when exposed to cancer cells, IFN- $\gamma$ secretion by CAR T cells significantly increased. As may be expected, ELISA data showed that higher MUC1 expressing PDA cells triggered higher levels of IFN- $\gamma$ and granzyme B release by CAR T cells. CTL T and mock T cells released negligible amount of IFN- $\gamma$ and granzyme B into the media even after exposure to target cells. Other controls including supernatants from (a) cancer cells alone and (b) Jurkat T cells, as well as (c) media alone, showed undetectable amounts of released IFN- $\gamma$ and granzyme B by ELISA (Figure 3A,B). The intracellular levels of IFN $\gamma$ (Figure S1B) and granzyme B (data not shown) in CAR T cells post exposure to PDA cells showed similar results to the ELISA. We further tested levels of intracellular perforin in CAR T cells before and after exposure to target cells by flowcytometry and the results showed no difference between resistant and sensitive target cells (Figure S1C).

A

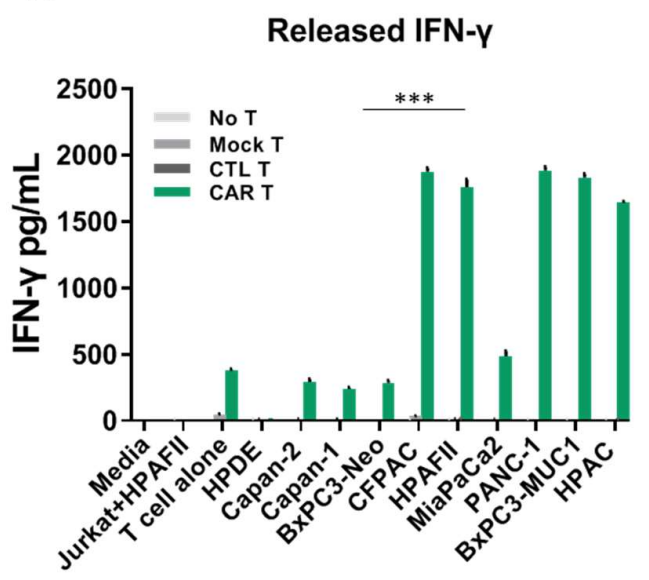

B

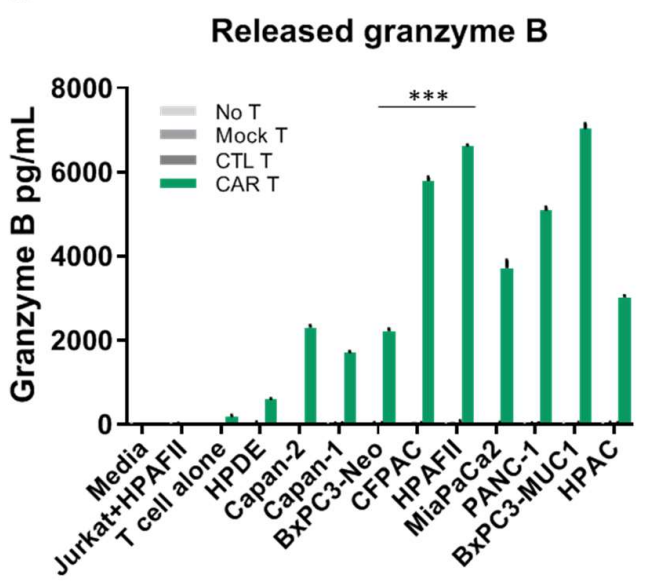

Figure 3. tMUC1-CAR-T cells produce IFN- $\gamma$ and granzyme B upon activation and antigen recognition. The amount of released IFN- $\gamma(\mathbf{A})$ and granzyme B $(\mathbf{B})$ in the co-culture media of CAR T cells and cancer cells measured by sandwich ELISA. Controls include supernatant of (1) cancer cells alone, (2) Jurkat and HPAFII cells co-culture, (3) T cells alone, as well as (4) media alone. The cancer cells are ordered based on their MUC1 level from left to right (low to high MUC1). tMUC1-CAR T cells exposed to cancer cells produce significant amount of IFN- $\gamma$ and granzyme B, while CTL T and mock T cells exposed to cancer cells produce negligible amount of IFN-y and granzyme B. CAR T cells exposed to normal epithelial cell line, HPDE, did not release noticeable amount of IFN- $\gamma$ and granzyme B. Significance is determined by comparing CAR T vs. mock T groups for each cell line. Error bars, SEM. $n=4$. Student's t-test, ${ }^{* * *} p<0.0005$ for CAR T cells vs. mock T cells.

\section{4. tMUC1-CAR T Cells Control Pancreatic Tumor Growth In Vivo}

To investigate the efficacy of CAR T cells in hampering tumor growth in vivo, an orthotopic mouse model of human PDA was stablished by injecting $0.5 \times 10^{6} \mathrm{MiaPaCa} 2-\mathrm{Luc}$ cells into the pancreas of NSG mice. Seven days post-surgery, mice were imaged using IVIS and tumor presence was confirmed. On day 8 post-surgery, mice were randomized into two groups based on their baseline luminescence intensity. One group received an IV injection of mock T and the other received CAR T cells $\left(10 \times 10^{6}\right.$ per mouse) (Figure 4A). Tumor growth was monitored using weekly IVIS imaging and the serial images are shown in Figure 4B. On day 68 post-surgery, mice were sacrificed and tumors were harvested. Mock T cell-treated mice had significantly larger tumors than CAR T cell-treated mice (Figure 4C). 
Many metastasis lesions were present on organs in the abdominal cavity of mock $\mathrm{T}$ cell-treated mice, whereas CAR T cell-treated mice had more confined tumors (Figure S5B). Tumor wet weights were measured and results showed a significant difference between the CAR T and mock $\mathrm{T}$ cell treated groups ( $p=0.0476$, Figure $4 \mathrm{D})$.

A

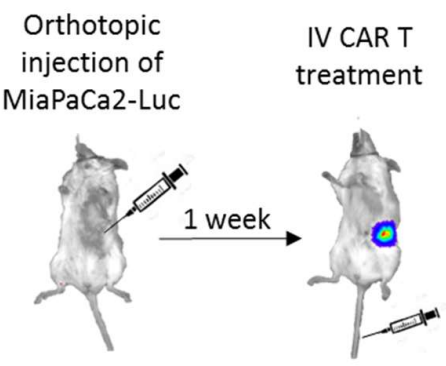

C

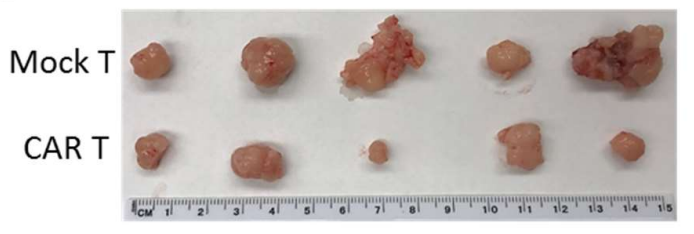

$\mathrm{E}$

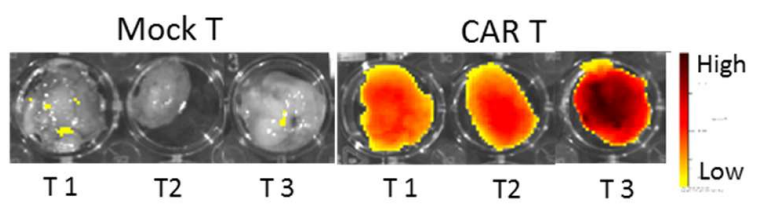

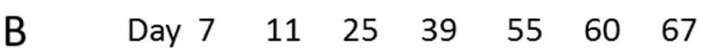

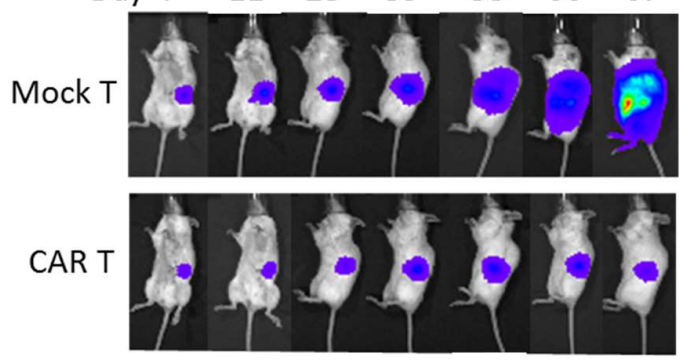

D

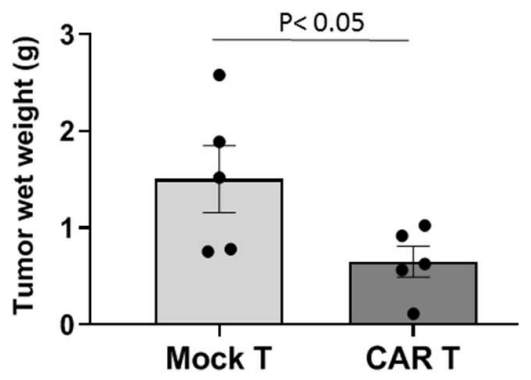

Figure 4. tMUC1-CAR T cells control pancreatic tumor growth in vivo. (A) Establishing the mouse model of human PDA using orthotopic injection of MiaPaCa2-Luc cancer cells into the pancreas. 7 days post-surgery, tumor presence was confirmed using in vivo imaging system (IVIS). On day 8, mice were randomized into two groups and injected IV with $10 \times 10^{6}$ mock or CAR T cells. Images were taken 8 min after luciferin injection using IVIS system. (B) Serial IVIS images of MiaPaCa2-Luc implanted mice treated with mock or CAR T started on day 7 post tumor inoculation. One mouse per group is shown as representative of 6 mice. (C) Images of the tumors harvested from mice treated with mock $\mathrm{T}$ or CAR T cells on day 68 post tumor inoculation. (D) Tumor wet weights of the mice treated with mock T or CAR T cells on day 68 after tumor inoculation. Significance of data was evaluated using Non-parametric Mann-Whitney U test. $p=0.05(n=5)$. (E) Visual representation of CAR T cells trafficking in the pancreatic tumors. To evaluate $\mathrm{T}$ cells trafficking into the fibrotic pancreatic tumor, six tumor-bearing mice (day 52 post-surgery) were injected IV with either $4 \times 10^{6}$ vivotrack-680 labeled-CAR T or mock T cells. After $24 \mathrm{~h}$, mice were scarified and tumors were harvested and imaged using fluorescent channel on IVIS machine with excitation $=676$ and emission $=696 \mathrm{~nm}$. The fluorescent signal acquired from tumors of mice treated with CAR T cells was significantly higher than the ones treated with mock $\mathrm{T}$ cells, which indicates more CAR T cells are directed to the tumor site than mock T cells. T1-3, tumor 1-3.

To see if CAR T cells can successfully traffic into the fibrotic pancreatic tumors, mock and CAR T cells were labeled with Vivotrack-680 dye and IV injected into six MiaPaCa2-Luc tumor-bearing NSG mice on day 52 post-surgery $(n=3)$. Mice were sacrificed $24 \mathrm{~h}$ after (since Vivotrack-680 signal intensity peaks at $24 \mathrm{~h}$ ), and tumors were dissected and imaged by IVIS using Vivotrack-680 channel. There was a strong signal emitted from CAR T cell-injected tumors compared to the control group, which suggests that CAR T cells were able to infiltrate into and localize in the pancreatic tumor mass as early as $24 \mathrm{~h}$ after infusion, while mock T cells were not directed to the tumor mass (Figure 4E). 
3.5. Deciphering the Intrinsic Resistance Mechanism Utilized by PDA Cells to CAR T Cell Therapy: Role of IDO1 and Gal-9

To assess why some PDA cell lines are resistant to CAR T cell killing independent of their tMUC1 expression or the CAR T cell's ability to express perforin (Figure S1C), or produce IFN- $\gamma$ and granzyme B (Figure 3 and Figure S1B), we considered some common immune evasion tactics used by tumor cells. We selected two highly resistant cell lines; HPAFII and CFPAC (both express similar levels of tMUC1, Figure 2B). As control, we included a highly sensitive cell line, MiaPaCa2, with a similar tMUC1 level.

Impairing $\mathrm{T}$ cells function by cancer cells is reported as a common mechanism involved in tumor immune evasion. The main factors in T cells anti-tumor cytotoxicity include IFN $\gamma$, granzyme B, and perforin secretion. Results show no correlation between the amount of released IFN $\gamma$ and granzyme $B$ and levels of intracellular perforin with the resistance of tumor cells (Figure 3 and Figure S1B,C).

Another common mechanism of immune evasion is associated with tumor-induced apoptosis of effector T cells. PDL1 expressed by cancer cells can interact with PD1 receptor on T cells and trigger T cell apoptosis. To test if HPAFII and CFPAC utilize this mechanism, mock and CAR T cells were exposed to resistant (HPAFII, CFPAC) or sensitive (MiaPaCa2) cells for 24, 48, and $72 \mathrm{~h}$ and the apoptosis was assessed by Annexin V/PI staining and flowcytometry. Data shows that apoptosis of mock and CAR T cells did not significantly alter after 24,48 , and $72 \mathrm{~h}$ exposure to resistant vs. sensitive PDA cells. T cell apoptosis level at $48 \mathrm{~h}$ time-point is shown in Figure 5A. Levels of PD1 expression by $\mathrm{T}$ cells before and after exposure to resistant or sensitive cells were measured by flowcytometry and the results are shown in Figure S2A,B. There was no significant difference between levels of PD1 expression by mock and CAR T cells before and after co-culture with resistant or sensitive cells at 24, 48, and $72 \mathrm{~h}$. Most PDA cells used in this study express considerable amounts of PDL1; however, the PDL1 level is not correlated with the resistance of PDA cells (Figure S2B). To confirm the results, PD1 blocking with anti-PD1 Ab was performed in combination with CAR T cell therapy on the three cell lines. We detected no improvement in the killing of the resistant PDA cell lines (HPAFII, CFPAC), while sensitive cell line (MiaPaCa2) killing was enhanced (Figure S4A). Data suggests that PD1/PDL1 interaction may not be the major factor driving CAR T cell resistance in HPAFII and CFPAC cells.

Because apoptosis of CAR T cells was not significantly different when co-cultured with resistant versus sensitive PDA cell lines, we enumerated cell numbers post co-culture. Proliferation of CAR $\mathrm{T}$ and mock $\mathrm{T}$ cells was evaluated before and after co-culture with resistant (HPAFII and CFPAC) and sensitive (MiaPaCa2) PDA cells at 24, 48, and $72 \mathrm{~h}$ using a cell counter. Interestingly, CAR T cell proliferation was significantly hindered when co-cultured with HPAFII and CFPAC cells by $72 \mathrm{~h}$, while enhanced when co-cultured with MiaPaCa2 cells. Mock T cell proliferation did not show the same trend (Figure 5B).

Studies have shown that PDA cells shed MUC1 into the supernatant and that may impair T cells function. It is also reported that depletion of soluble MUC1 from the tumor supernatants reversed the inhibitory effects on T cells [32]. Thus, we assessed the amount of released MUC1 by PDA cells in the co-culture media using a specific ELISA (Figure S2C). Results showed that only HPAC cell released high level of MUC1, while other PDA cells shed minimal levels of MUC1. Since the HPAC cell line is highly sensitive to CAR T cell treatment, we negated the role of shed MUC1 as a mechanism for antigen loss and immune escape (Figure S2C). 
A

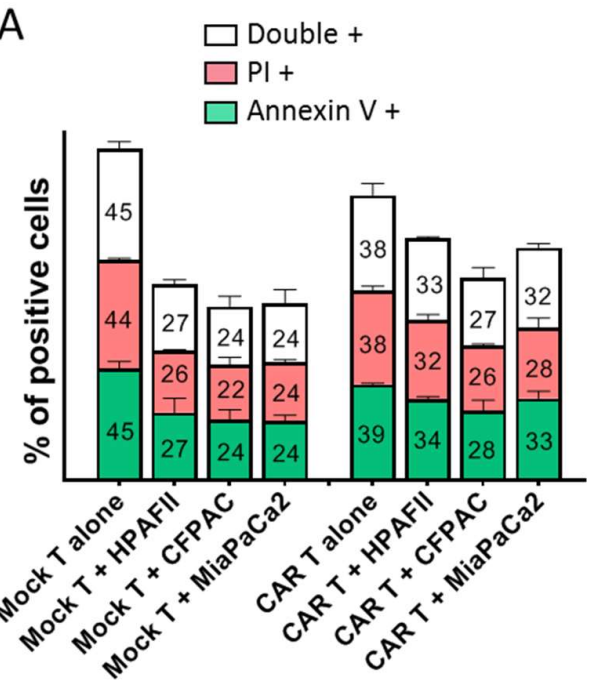

B
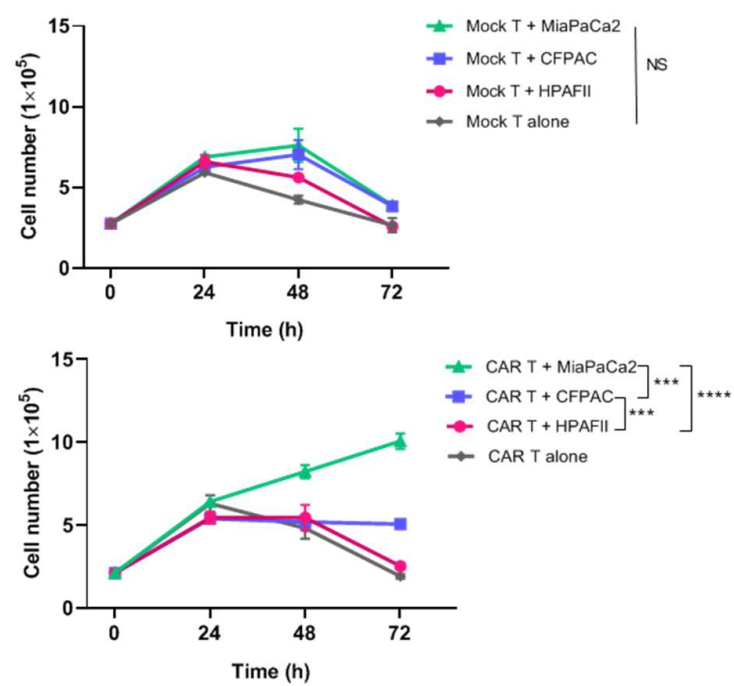

C
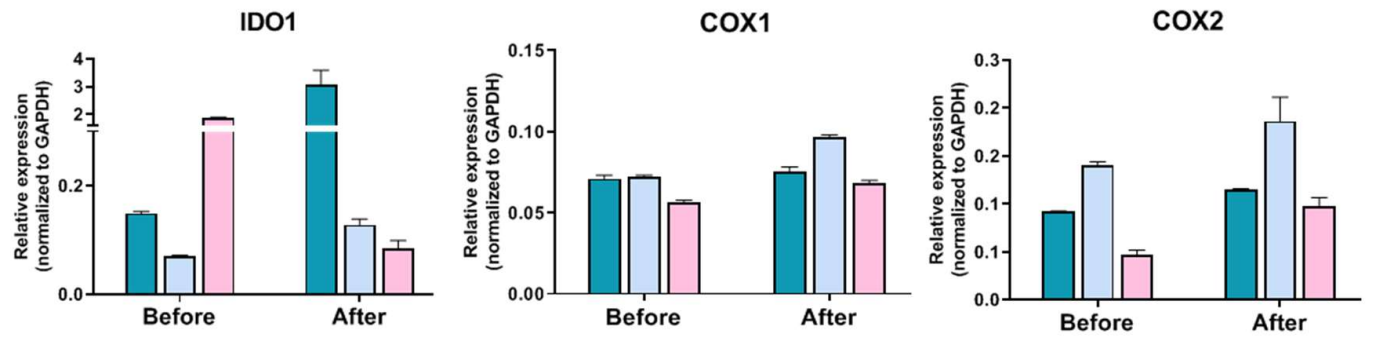

ADAR1
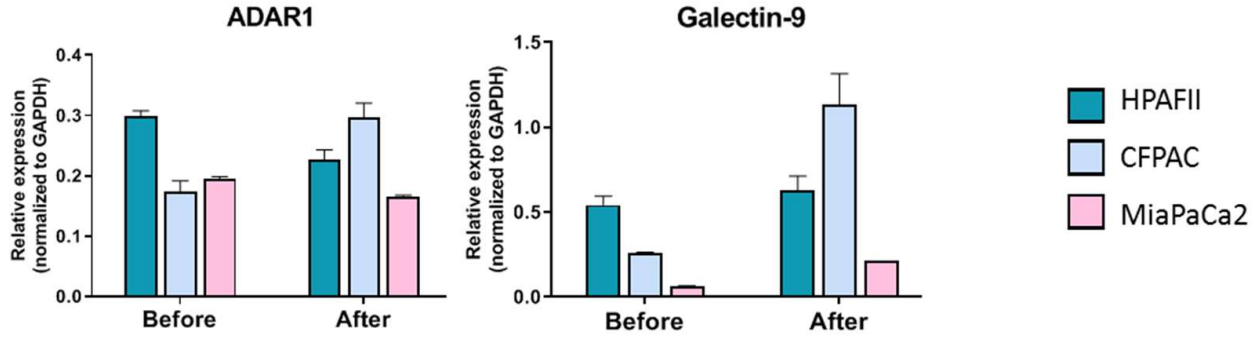

Figure 5. Deciphering the resistance mechanism utilized by PDA cells against CAR $T$ cell therapy. (A) Apoptosis of CAR T cells before and after exposure to HPAFII, CFPAC, and MiaPaCa2 cells. Mock and CAR T cells were co-cultured with PDA cells and their apoptosis level was measured by Annexin $\mathrm{V} / \mathrm{PI}$ staining at 24,48 , and $72 \mathrm{~h}$ post co-culture. (A) shows the average percentage of positive Annexin $\mathrm{V}, \mathrm{PI}$, or both in T cells after $48 \mathrm{~h}$ co-culture. Statistical analysis with one-way ANOVA comparing the mean of three groups (CAR T + HPAFII vs. CFPAC and vs. MiaPaCa2) showed no difference between apoptosis levels of CAR T cells. (B) Mock and CAR T cells proliferation over time after exposure to HPAFII, CFPAC, and MiaPaCa2 cells. T cells were enumerated using an automated cell counter. MiaPaCa2 cells enhanced proliferation of CAR T cells after 48 and $72 \mathrm{~h}$, whereas CFPAC and HPAFII cells hindered CAR T cells proliferation. Mock T cells did not show the same trend. Significance of data was evaluated using two-way ANOVA (Multiple Comparison). Error bars, SEM. ${ }^{* * *} p<0.001$, $* * * * p<0.0001$. (C) q-PCR data showing relative expression level of five important genes in HPAFII, CFPAC, and MiaPaCa2 cells before and after exposure to CAR T cells. CTs are normalized to GAPDH in each sample and a higher number in $Y$-axis represents higher expression of the gene. IDOI, COX1/2, ADAR1, and galectin-9 genes were overexpressed in resistant PDA cells after exposure to CAR T cells. For more details, see Figure S3. Error bars, SEM. $n=3$. 
Thus, we moved to investigate the gene expression profile of HPAFII, CFPAC, and MiaPaCa2 cells. Sixteen genes linked to immune resistance (based on literature) were analyzed using qPCR technique (Figure S3). Most of the genes were expressed at low levels in resistant cells, except IDO1, COX1/2, ADAR1, and Gal-9 (Figure 5C and Figure S3). Figure 5C shows relative expression of these five genes (normalized to GAPDH) in three cell lines before and after CAR T cell treatment. MUC1 mRNA expression in resistant vs. sensitive cells did not significantly change after CAR T cell treatment, indicating no antigen loss through gene downregulation, and therefore may not account for the immune evasion in the HPAFII and CFPAC PDA cells (Figure S3). According to qPCR data, IDO1 gene expression in HPAFII cells was significantly increased (69-fold increase) after treatment with CAR $\mathrm{T}$ cells, while its level declined in MiaPaCa2 cells. COX1 and 2 expressions were slightly higher in HPAFII and CFPAC, and their level increased after CAR T treatment. The expression of ADAR1 gene was higher in HPAFII cells compared to MiaPaCa2 before treatment, and expression of this gene was only increased in CFPAC after CAR T treatment. Gal-9 gene expression was also high in both resistant cells before and after CAR T cell therapy. These genes are appropriate candidates to further study, as some of the important players in immune resistance of HPAFII and CFPAC cells. Hence, we combined CAR T cell treatment with inhibitors or blocking antibodies to the above-mentioned molecules.

\subsection{Battling the Resistance of PDA Cells with Combination Therapy}

\subsubsection{Targeting Resistance Related Genes with Small Molecule Inhibitors and Blocking Antibody}

IDO1 was one of the candidate genes involved in immune resistance. IDO1 function can be inhibited by 1-MT drug. Three cell lines were treated with 1-MT at three different concentrations for 1 day followed by 3 days of mock or CAR T cell treatment. CAR T cells and drug killing was normalized to mock $\mathrm{T}$ cell plus drug, and the asterisk shows significant difference between the CAR T cells plus drug (combination therapy) and CAR T cells alone. Results showed a significant reduction in survival of HPAFII and CFPAC cells by combination of CAR T cells and 1-MT therapy in a dose dependent manner compared to CAR T alone or 1-MT alone therapy, while MiaPaCa2 cells showed no significant difference in survival (Figure 6). Data suggests that IDO1 may be one of the major factors causing immune resistance in HPAFII and CFPAC cells, and targeting IDO1, along with CAR T cell therapy, may enhance the treatment efficacy in resistant PDA cells.

Several studies have shown the importance of COX1 and COX2 in causing resistance of cancer cells to immune therapy [33]. Therefore, celecoxib (specific COX-2 inhibitor) and indomethacin (COX1 and 2 inhibitor) were used in combination with CAR T cells. Both HPAFII and CFPAC cells showed reduction in survival when treated with indomethacin and CAR T cells, while MiaPaCa2 cells showed no difference in survival (Figure 6). Celecoxib did not change the efficacy of CAR T cells (data not shown).

The next candidate gene for resistance was ADAR1. qPCR data showed an elevation in ADAR1 gene expression level in resistant cells compared to MiaPaCa2. PDA cells were treated with EHNA drug (ADAR1 inhibitor) for $24 \mathrm{~h}$ before adding CAR T cells, and cell survival was measured at $72 \mathrm{~h}$ post co-culture. Combination therapy with EHNA drug did not result in a significant reduction in the survival of the target cells (Figure S4B). Hence, we inferred that ADAR1 might not play an important role in immune resistance of HPAFII and CFPAC cells. 
1-MT
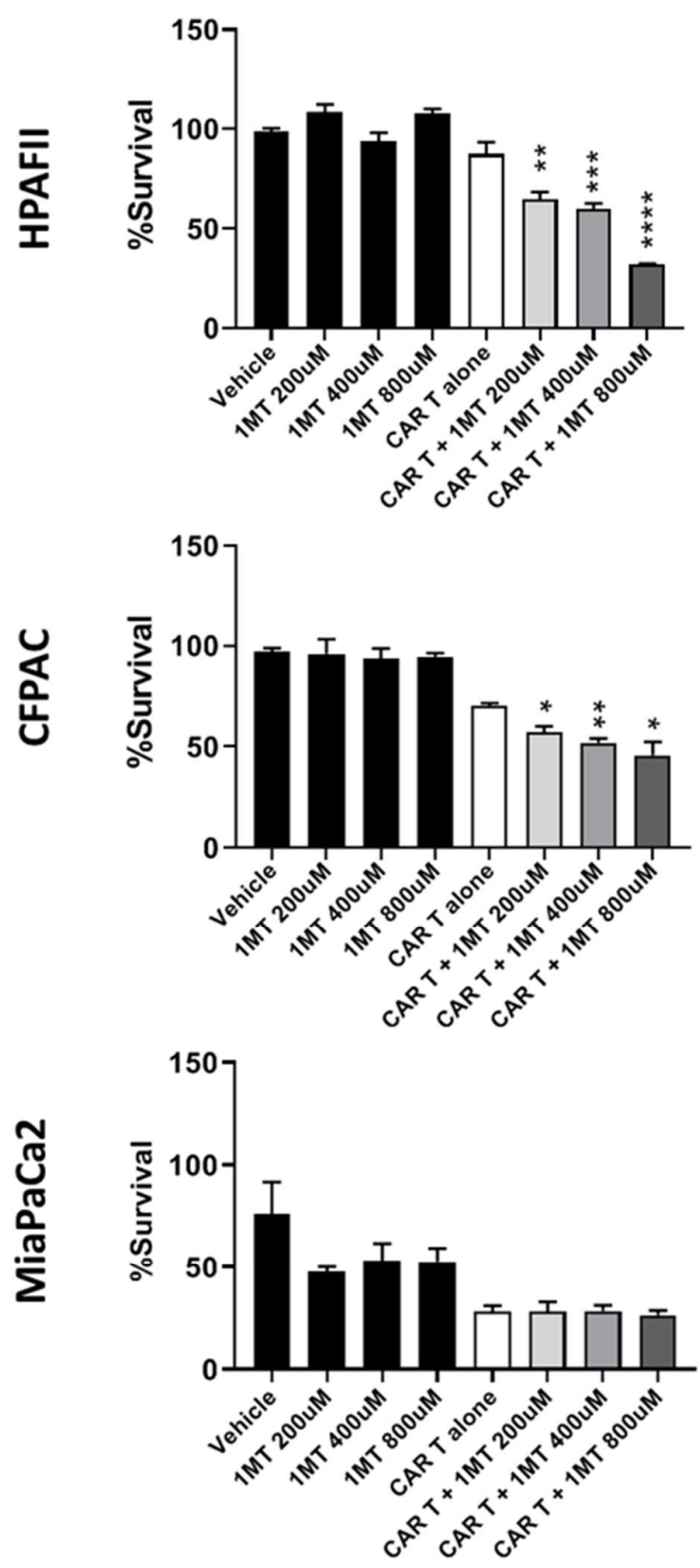

Indomethacin
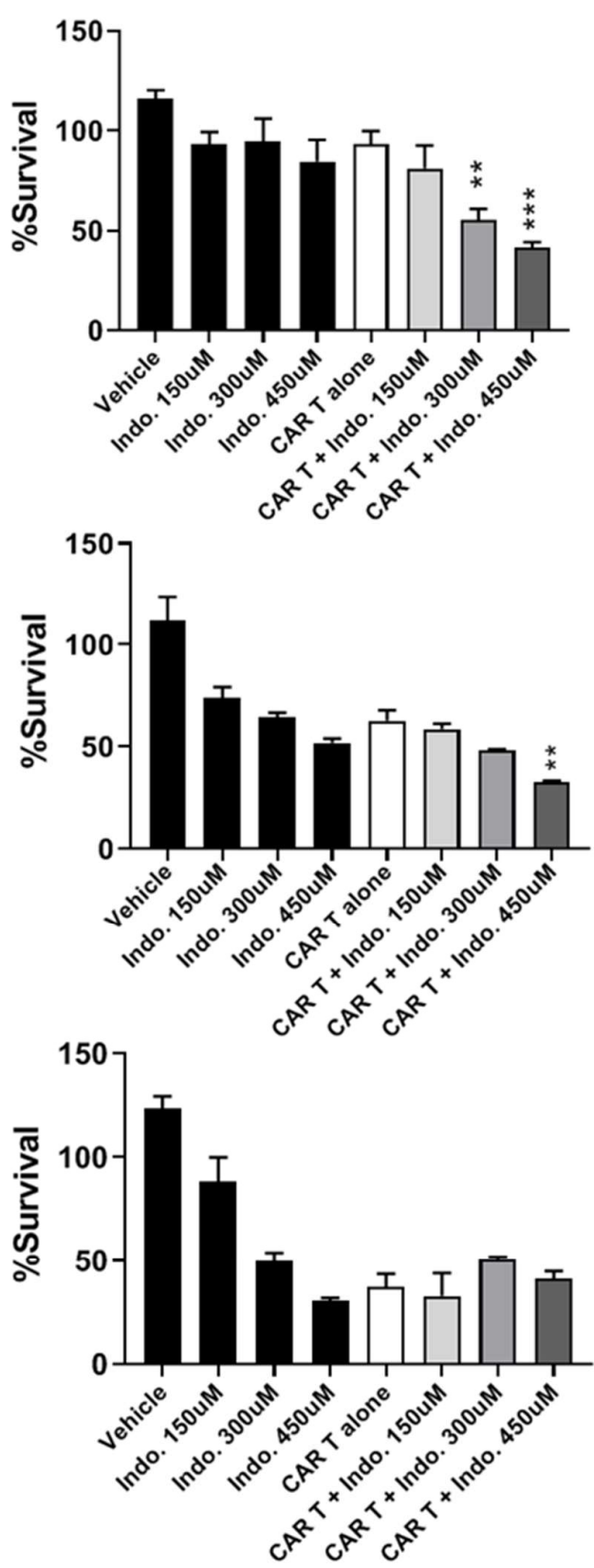

Figure 6. Targeting resistance related genes with small molecule inhibitors. HPAFII, CFPAC, and MiaPaCa2 cells were pre-treated with indoleamine 2, 3-dioxygenases-1 (IDO1) inhibitor (1-MT) or COX1/2 inhibitor (indomethacin) for $24 \mathrm{~h}$, then drugs were removed and PDA cells were co-cultured with mock or CAR T cells for $72 \mathrm{~h}$ at T:E ratio of 1:10. Percentage survival was measured using MTT assay and normalized to mock T. HPAFII and CFPAC killing by CAR T cells was significantly improved when pre-treated with 1-MT and indomethacin; while MiaPaCa2 cell did not respond to the combinational treatment. Student's $t$-test comparing CAR $\mathrm{T}+$ drug group to CAR $\mathrm{T}$ alone group. ${ }^{*} p<0.05,{ }^{* *} p<0.01,{ }^{* * *} p<0.001,{ }^{* * * *} p<0.0001$. Error bars, SEM. $n=4$.

Gal-9 was another gene that showed increased expression in the resistant cells. Gal-9 is a tandem-repeat galectin interacting with Tim3 receptor on T cells [34]. To neutralize the effects of Gal-9, a blocking Ab, 9M1-3, was used in combination with CAR T cells and the results are shown in Figure 7. HPAFII and CFPAC cells are efficiently targeted by CAR T cells when Gal-9 checkpoint inhibitor is added to the co-culture media, compared to CAR T cell or 9M1-3 treatment alone. In contrast, the 
survival of MiaPaCa2 cells was not affected by the combination. Data suggests that the Gal-9-Tim3 interaction may play an important role in immune evasion by resistant PDA cells.
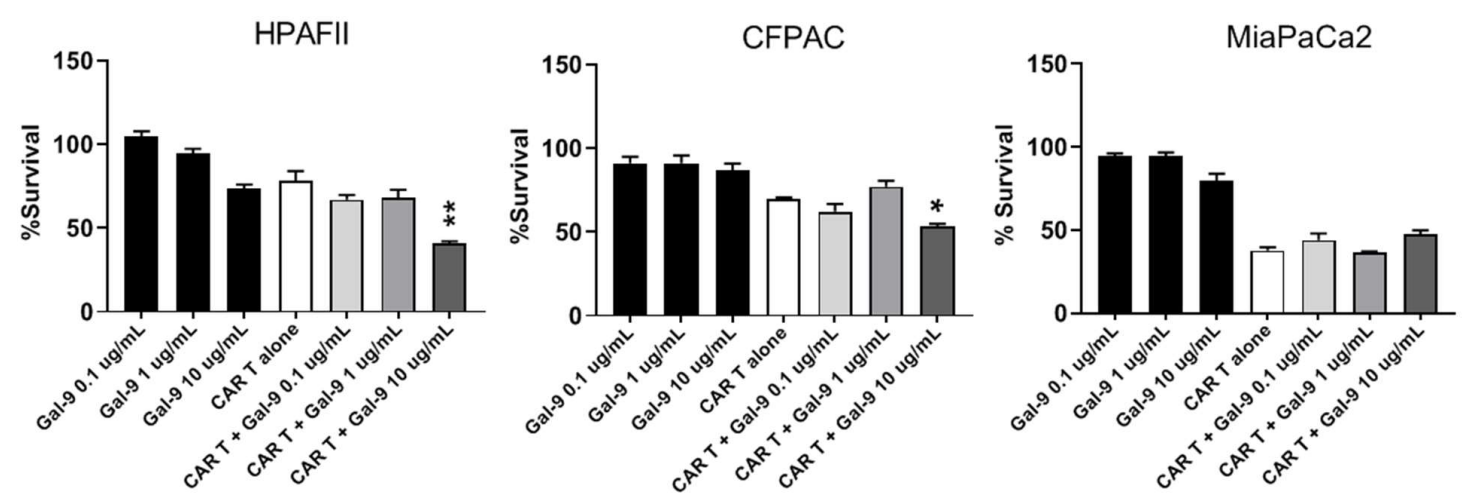

Figure 7. Targeting resistance related genes with anti-Gal-9 blocking Ab. Percentage survival of HPAFII, CFPAC, and MiaPaCa2 cells after treatment with CAR T alone, Gal-9 blocking Ab alone, and combination of CAR T cell and Gal-9 blocking Ab. Anti-Gal-9 Ab was added at three different concentrations to the co-culture media of PDA cells and mock or CAR T cells (T:E 1:10). Percentage survival was obtained using MTT assay and data was normalized to mock T. HPAFII and CFPAC survival were reduced with combination of CAR T and anti-Gal-9 blocking Ab; while MiaPaCa2 did not respond to the combination therapy. Student's $t$-test comparing CAR T + anti-Gal-9 Ab group to CAR T alone group. ${ }^{*} p<0.05,{ }^{* *} p<0.01$. Error bars, SEM. $n=4$.

In summary, we demonstrate that (a) 1-MT was synergistic with CAR T cell therapy in killing of HPAFII and CFPAC in all three doses; (b) Indomethacin was synergistic with CAR T cell in treating HPAFII cell; yet, it showed additive effect in treating CFPAC; and (c) anti-Gal-9 Ab (10 $\mu \mathrm{g})$ was synergistic with CAR T cells in treating HPAFII and CFPAC.

3.6.2. tMUC1-CAR T Cells Work Synergistically with Common Chemotherapy Drugs to Kill Resistant PDA Cells

Another approach to break the resistance of target cells to CAR T cells is pre-sensitizing them with common chemotherapy drugs. Three widely used drugs for PDA include gemcitabine (GEM), 5-Fluorouracil (5-FU), and paclitaxel (PTX). GEM is an analog of deoxycytidine, thereby inhibits DNA synthesis; PTX suppresses microtubule detachments from centrosome; and 5-FU inhibits thymidine synthase. We treated PDA cells with the drugs for $24 \mathrm{~h}$ prior to CAR T cell treatment. After $72 \mathrm{~h}$ of CAR T treatment, target cell viability was measured using MTT assay. Results demonstrate significantly enhanced sensitivity of HPAFII cells to CAR $T$ cell treatment when pre-exposed to low-dose chemotherapy drugs (Figure 8, top row). All three drugs improved killing of HPAFII cells with CAR T cells (synergistically), while only 5-FU showed the same effect on CFPAC cells (additively). GEM and PTX did not assist the CFPAC sensitivity to CAR T cells (Figure 8, bottom row). Data suggests that pre-sensitizing the resistant PDA cells with a low dose of appropriate chemotherapeutic drug may enhance the efficacy of CAR T cell treatment. 
Gemcitabine
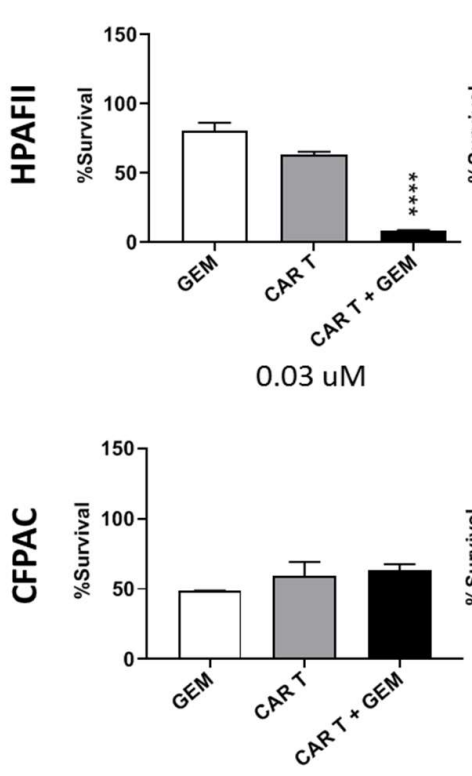

0.03 uM
Paclitaxel
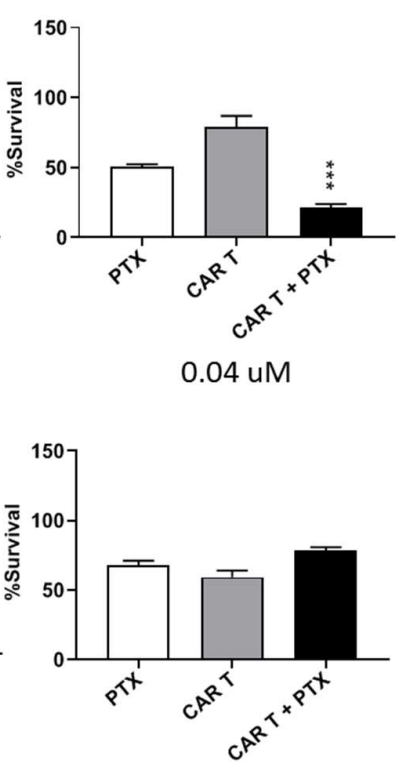

0.06 uM
5-FU
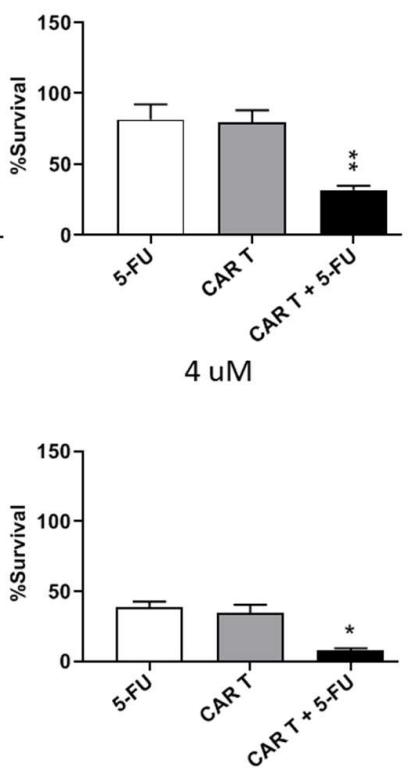

3 uM

Figure 8. tMUC1-CAR T cells work synergistically with common chemotherapy drugs to kill resistant PDA cells. Percentage survival of two resistant PDA cells, HPAFII and CFPAC, treated with combination of CAR T and chemotherapy drugs. HPAFII and CFPAC were exposed to gemcitabine, paclitaxel, or 5-FU for $24 \mathrm{~h}$ at indicated concentrations, then co-cultured with mock or CAR T cells at T:E ratio of 1:10. The survival level was measured using MTT assay and data was normalized to mock T. Student's $t$-test comparing CAR T + drug to CAR T alone group, ${ }^{*} p<0.05,{ }^{* *} p<0.0021,{ }^{* * *} p<0.0004,{ }^{* * * *} p<0.0001$. Error bars, SEM. $n=4$.

\section{Discussion}

We presented preclinical data showing efficacy of a novel TAB004-derived CAR T cell targeting tMUC1 against a panel of human PDA cell lines. Data demonstrated that some PDA cells remain highly resistant to CAR T cell therapy. Thus, we determined the genes that may be involved in the immune resistance. Data clearly implicate IDO1, and to a lesser extent, COX1/2 and Gal-9 genes as mechanisms of CAR T cell resistance. To our knowledge, this is the first study to show that blocking the function of IDO1, COX1/2, or Gal-9 can enhance CAR T cells therapy against PDA cells. We also report that pre-treating the resistant HPAFII cells with standard drugs such as PTX, GEM, and 5-FU enhanced CAR T cell efficacy. However, for CFPAC cells, only pre-treatment with 5-FU enhanced CAR $T$ cell efficacy. Data suggest that not all PDA cells are alike, and biomarkers such as IDO1 and Gal-9 may be useful tools to determine a response to CAR T cell therapy.

Recently, a MUC1 CAR T cell using the scFv from a different MUC1 Ab was shown to be efficacious against breast and pancreatic tumors [17]. Our data corroborates that tumor-associated MUC1 remains a critical targetable antigen in PDA. This study differs from previously reported data, firstly by testing the efficacy of the tMUC1-CAR T cell against a large panel of PDA cell lines and normal epithelial and fibroblastic cells, and secondly by deciphering the potential intrinsic immune tolerance mechanisms utilized by PDA cells to resist CAR T cell therapy. Furthermore, this may be the first study indicating the role of Gal-9 in conferring resistance in PDA cells to CAR T cell treatment and that ADAR1 pathway was less critical in conferring resistance.

CAR T cell therapy, though extremely successful in treating hematopoietic cancers, has not gained momentum in the treatment of solid tumors [9]. This is primarily because of limited selection of tumor specific antigen and a dearth of specific antibodies against them. CAR based on antibodies which 
recognize a shared tumor antigen, such as ERBB2, have led to lethal outcomes [35]. Other MUC1 antibodies may be limited by their specificity, wherein they bind to tumor and normal MUC1. TAB004 has high specificity and binding to tMUC1 [24] and spares binding to normal MUC1. Recently, our group has published the effectiveness of tMUC1-CAR T cell efficacy against triple-negative breast cancer cells in vitro and in vivo [36]. This highlights the potency of tMUC1-CAR T cells as a potential therapy for multiple adenocarcinomas.

Despite many of the PDA cells being efficiently destroyed by CAR T cells, some PDA cells were highly resistant. This was not surprising since PDA is known to be immunologically cold and refractory to the treatments. Thus, deciphering mechanisms involved in PDA immune-resistance is of cardinal importance. The majority of combination therapies to date have focused on targeting the PD1/PDL1 axis using blocking antibodies [37], but in our study with HPAFII and CFPAC cells, we saw no evidence supporting enhanced CAR T cell efficacy when combined with anti-PD1 Ab [36]. A study by Koyama et al. [38] has shown that failure of PD1 monotherapy blockade or PD1 adaptive resistance in lung adenocarcinoma is associated with upregulation of alternative immune checkpoint molecules, particularly Tim-3. This may explain why PD1 blockade in our model did not improve HPAFII and CFPAC killing, dissimilar to MiaPaCa2 cells. Tim-3 upregulation in HPAFII and CFPAC cells with elevated levels of its ligand, Gal-9, may potentially deteriorate CAR T cells function.

Multiple factors can dictate the resistance of a tumor cells to a treatment. High-throughput screening is required and yet it may result in inconclusive data. In this study, we focused on key proteins and genes known to be associated with immune tolerance. Sixteen genes were analyzed using qPCR. Among those, IDO1, an enzyme that catabolizes tryptophan to kynurenine acid and thereby provides metabolic advantage to cancer cells against $T$ cells, was found to be of utmost importance $[39,40]$. IDO1 contributes to peripheral immune tolerance and evasion of tumors by downregulating $\mathrm{T}$ cell metabolism. Several studies have confirmed that IDO1 and the downstream tryptophan catabolites inhibit $\mathrm{T}$ cell proliferation, thereby suppressing $\mathrm{T}$ cell function [41-44]. The effect of tumor IDO on CD19-CAR T cell activity in a B cell lymphoma model has been shown [45]. In this study, we extend the finding that elevated IDO activity in PDA causes immune resistance to CAR T cells. As shown in our study, CAR T cell proliferation was stunted when co-cultured with resistant PDA cell line (Figure 5B). This reduction in proliferation may be due to elevated IDO1 activity and the release of tryptophan catabolites in the co-culture media. Accordingly, neutralizing the effect of IDOI by 1-MT drug resulted in improved lysis of HPAFII and CFPAC cells by CAR T cells. Data showed that 1-MT in combination therapy did not improve the CAR T cells cytotoxicity against MiaPaCa2 cells; however, $1 \mathrm{MT}$ alone did reduce the MiaPaCa2 cells survival by $50 \%$. These results may have occurred due to the presence of high level of IDO1 in MiaPaCa2 before the treatment and its low levels after the treatment. According to a previous study, IDO1 promotes cancer cell proliferation independent of its ability to limit T cell-mediated immune surveillance [46]. Accordingly, in our study, 1MT prior to CAR $\mathrm{T}$ cell therapy could neutralize the effect of IDO1 on MiaPaCa2 cell growth; however due to unknown mechanisms, IDO1 gene expression was decreased after CAR T cells therapy, which nullified the effect of 1MT.

Another gene with distinct overexpression in resistant cells was Gal-9. Gal-9 is a tandem-repeat type galectin that, like other galectins, modulates multiple biological functions such as cell adhesion and aggregation. Although the role of Gal-9 in immunity is controversial [47], many studies confirmed that Gal-9 negatively regulates T cells via interaction with Tim-3 receptor [34,48,49]. Tim-3 is a negative regulatory immune checkpoint expressed on $\mathrm{T}$ cell which is known to inhibit the immune responses of TH1 cells and plays an important role in immune exhaustion of T cells [50]. Studies have shown that interaction between Gal-9 and Tim-3 triggers cell death in effector Th1 cells [51] and in Tim- $3^{+} \mathrm{CD} 8^{+}$ tumor infiltrating lymphocytes [52]. However, not all Gal-9-Tim-3 interactions result in cell death, as Gal-9 was found to increase Tim-3-mediated IFN- $\gamma$ production in a NK cell line [53]. We have evaluated the level of Tim-3 expression on CAR T cells when exposed to resistant and sensitive target cells, but no significant difference was detected (data not shown). However, we found that targeting Gal-9 with 
a blocking $\mathrm{Ab}$ reduced tolerance of resistant HPAFII and CFPAC to tMUC1-CAR T cell therapy. Hence, the Gal-9 immunosuppressive role may be mediated through other less known mechanisms.

ADAR1 was noticeably overexpressed in HPAFII and CFPAC cells. ADAR1 regulates the biogenesis of members of the miR-222 family and thereby ICAM1 expression, which ultimately leads to immune resistance [54]. Loss of function of ADAR1 in tumor cells strongly sensitizes tumors to immunotherapy and overcomes resistance to PD1 checkpoint blockade [55]. Surprisingly, in this study, blocking ADAR1 function with an inhibitor, did not result in breaking the resistance of HPAFII and CFPAC cells to CAR T cells treatment.

Finally, COX1/2 are enzymes catalyzing the synthesis of prostaglandin E2 (PGE2), a major player in inflammation, angiogenesis, and immunosuppression in cancer [56,57]. COX2 is often overexpressed in cancer cells and is associated with progressive tumor growth, as well as resistance of cancer cells to conventional chemotherapy, immunotherapy, and radiotherapy [57]. COX1/2 inhibitors have been used in combination with anti-cancer agents and immunotherapy against cancers [58]. Indeed, indomethacin significantly improved CAR T cell efficacy when HPAFII cells were pre-treated with the drug. To our surprise, celecoxib had no such effect. This may indicate COX1 and 2 together play a more important role in HPAFII resistance to CAR T cells than COX2 by itself. This data is in line with other immunotherapy strategies, such as checkpoint blockades combined with COX2 inhibitors [33]. Further studies are needed in order to explain the molecular events governing the success or failure of these combination therapies.

Since tMUC1-CAR T cell is new, we wished to confirm other published studies that combined CAR T cell treatment with standard of care chemotherapy drugs $[59,60]$. Data from this study clearly corroborates previous findings. Pre-treating resistant HPAFII cells with suboptimal dose of GEM, PTX, or 5-FU significantly enhanced CAR T cell cytotoxicity. To our surprise, PTX and GEM did not have the same effect on the CFPAC. In CFPAC, only 5-FU was effective in enhancing CAR T cell treatment. Thus, we strongly believe that every tumor is different and responds differently to drugs and immunotherapy. These results provide a promising strategy for the potentiation of CAR T therapy in treating refractory PDA tumors.

Based on the in vivo orthotopic model of MiaPaCa2 tumors, tMUC1-CAR T cells could clearly reduce tumor burden but could not eradicate the tumor. To improve the treatment efficacy, several strategies can be utilized in the future, such as multiple injections of CAR T cells, combination with the other drugs mentioned above, and in the future, using an immunocompetent model of PDA. Testing CAR T cells function in a human MUC1 transgenic mouse model of spontaneous PDA is currently underway by our group. In summary, our results provide promise for the use of tMUC1-CAR T cells against treatment refractory PDA in combination with inhibitors against IDO1, COX1/2, and Gal-9 or in combination with low-dose standard chemotherapy drugs.

Supplementary Materials: Supplementary Materials are available online at http://www.mdpi.com/2073-4409/8/9/ 1070/s1.

Author Contributions: Conceptualization, M.Y., R.Z. and P.M.; methodology, M.Y., R.Z., D.D. and P.M.; validation, M.Y., R.Z. and P.M.; formal analysis, M.Y. and P.M.; investigation, M.Y., R.Z., P.G., S.-t.W., C.W., M.B. and L.J.M.; resources, P.M., J.M. and C.W.; writing — original draft preparation, M.Y.; writing—review and editing, M.Y. and P.M.; visualization, M.Y. and P.M.; supervision, R.Z. and P.M.; project administration, P.M.; funding acquisition, P.M.

Funding: This research was funded by NIH, grant numbers R01 CA135650-05A1 and R15 CA173668-01.

Acknowledgments: We thank Richard Chi for helping with the microscopy. We are thankful to Timothy Erick for editing the manuscript. We also thank our vivarium staff members for their assistance with training and animal care.

Conflicts of Interest: Pinku Mukherjee is a board member of OncoTab, Inc. The other authors declare that they have no conflict of interest. 


\section{References}

1. Hidalgo, M.; Cascinu, S.; Kleeff, J.; Labianca, R.; Löhr, J.M.; Neoptolemos, J.; Real, F.X.; Van Laethem, J.-L.; Heinemann, V. Addressing the challenges of pancreatic cancer: Future directions for improving outcomes. Pancreatology 2015, 15, 8-18. [CrossRef] [PubMed]

2. Kamisawa, T.; Wood, L.D.; Itoi, T.; Takaori, K. Pancreatic cancer. Lancet (London, England) 2016, 388 , $73-85$. [CrossRef]

3. Yabar, C.S.; Winter, J.M. Pancreatic Cancer: A Review. Gastroenterol. Clin. N. Am. 2016, 45, 429-445. [CrossRef] [PubMed]

4. Swayden, M.; Iovanna, J.; Soubeyran, P. Pancreatic cancer chemo-resistance is driven by tumor phenotype rather than tumor genotype. Heliyon 2018, 4, e01055. [CrossRef] [PubMed]

5. Srivastava, S.; Riddell, S.R. Engineering CAR-T cells: Design concepts. Trends Immunol. 2015, 36, 494-502. [CrossRef] [PubMed]

6. Kalos, M.; Levine, B.L.; Porter, D.L.; Katz, S.; Grupp, S.A.; Bagg, A.; June, C.H. T cells with chimeric antigen receptors have potent antitumor effects and can establish memory in patients with advanced leukemia. Sci. Transl. Med. 2011, 3, 95ra73. [CrossRef] [PubMed]

7. Kochenderfer, J.N.; Dudley, M.E.; Feldman, S.A.; Wilson, W.H.; Spaner, D.E.; Maric, I. B-cell depletion and remissions of malignancy along with cytokine-associated toxicity in a clinical trial of anti-CD19 chimeric-antigen-receptor-transduced T cells. Blood 2012, 119. [CrossRef]

8. Rosenberg, S.A.; Yannelli, J.R.; Yang, J.C.; Topalian, S.L.; Schwartzentruber, D.J.; Weber, J.S.; Parkinson, D.R.; Seipp, C.A.; Einhorn, J.H.; White, D.E. Treatment of Patients With Metastatic Melanoma With Autologous Tumor-Infiltrating Lymphocytes and Interleukin 2. J. Natl. Cancer Inst. 1994, 86, 1159-1166. [CrossRef]

9. Yazdanifar, M.; Zhou, R.; Mukherjee, P. Emerging immunotherapeutics in adenocarcinomas: A focus on CAR-T cells. Curr. Trends Immunol. 2016, 17, 95-115.

10. Cheever, M.A.; Allison, J.P.; Ferris, A.S.; Finn, O.J.; Hastings, B.M.; Hecht, T.T.; Mellman, I.; Prindiville, S.A.; Viner, J.L.; Weiner, L.M.; et al. The prioritization of cancer antigens: A national cancer institute pilot project for the acceleration of translational research. Clin. Cancer Res. 2009, 15, 5323-5337. [CrossRef]

11. Levi, E.; Klimstra, D.S.; Adsay, N.V.; Andea, A.; Basturk, O. MUC1 and MUC2 in pancreatic neoplasia. J. Clin. Pathol. 2004, 57, 456-462. [CrossRef] [PubMed]

12. Chhieng, D.C.; Benson, E.; Eltoum, I.; Eloubeidi, M.A.; Jhala, N.; Jhala, D.; Siegal, G.P.; Grizzle, W.E.; Manne, U. MUC1 and MUC2 expression in pancreatic ductal carcinoma obtained by fine-needle aspiration. Cancer 2003, 99, 365-371. [CrossRef] [PubMed]

13. Schroeder, J.A.; Masri, A.A.; Adriance, M.C.; Tessier, J.C.; Kotlarczyk, K.L.; Thompson, M.C.; Gendler, S.J. MUC1 overexpression results in mammary gland tumorigenesis and prolonged alveolar differentiation. Oncogene 2004, 23, 5739-5747. [CrossRef] [PubMed]

14. Sahraei, M.; Roy, L.D.; Curry, J.M.; Teresa, T.L.; Nath, S.; Besmer, D.; Kidiyoor, A.; Dalia, R.; Gendler, S.J.; Mukherjee, P. MUC1 regulates PDGFA expression during pancreatic cancer progression. Oncogene 2012, 31, 4935-4945. [CrossRef] [PubMed]

15. Beatty, G.L.; Haas, A.R.; Maus, M.V.; Torigian, D.A.; Soulen, M.C.; Plesa, G.; Chew, A.; Zhao, Y.; Levine, B.L.; Albelda, S.M.; et al. Mesothelin-specific chimeric antigen receptor mRNA-engineered T cells induce anti-tumor activity in solid malignancies. Cancer Immunol. Res. 2014, 2, 112-120. [CrossRef] [PubMed]

16. Hudecek, M.; Lupo-Stanghellini, M.T.; Kosasih, P.L.; Sommermeyer, D.; Jensen, M.C.; Rader, C.; Riddell, S.R. Receptor affinity and extracellular domain modifications affect tumor recognition by ROR1-specific chimeric antigen receptor T cells. Clin. Cancer Res. 2013, 19, 3153-3164. [CrossRef] [PubMed]

17. Wilkie, S.; Picco, G.; Foster, J.; Davies, D.M.; Julien, S.; Cooper, L.; Arif, S.; Mather, S.J.; Taylor-Papadimitriou, J.; Burchell, J.M.; et al. Retargeting of human T cells to tumor-associated MUC1: The evolution of a chimeric antigen receptor. J. Immunol. 2008, 180, 4901-4909. [CrossRef] [PubMed]

18. Wilkie, S.; van Schalkwyk, M.C.; Hobbs, S.; Davies, D.M.; van der Stegen, S.J.; Pereira, A.C.; Burbridge, S.E.; Box, C.; Eccles, S.A.; Maher, J. Dual targeting of ErbB2 and MUC1 in breast cancer using chimeric antigen receptors engineered to provide complementary signaling. J. Clin. Immunol. 2012, 32, 1059-1070. [CrossRef]

19. Anurathapan, U.; Chan, R.C.; Hindi, H.F.; Mucharla, R.; Bajgain, P.; Hayes, B.C.; Fisher, W.E.; Heslop, H.E.; Rooney, C.M.; Brenner, M.K.; et al. Kinetics of tumor destruction by chimeric antigen receptor-modified T cells. Mol. Ther. 2014, 22, 623-633. [CrossRef] 
20. You, F.; Jiang, L.; Zhang, B.; Lu, Q.; Zhou, Q.; Liao, X.; Wu, H.; Du, K.; Zhu, Y.; Meng, H.; et al. Phase 1 clinical trial demonstrated that MUC1 positive metastatic seminal vesicle cancer can be effectively eradicated by modified Anti-MUC1 chimeric antigen receptor transduced T cells. Sci. China Life Sci. 2016, 59, 386-397. [CrossRef] [PubMed]

21. Roy, L.D.; Dillon, L.M.; Zhou, R.; Moore, L.J.; Livasy, C.; El-Khoury, J.M.; Puri, R.; Mukherjee, P. A tumor specific antibody to aid breast cancer screening in women with dense breast tissue. Genes Cancer 2017, 8 , 536-549. [CrossRef] [PubMed]

22. Moore, L.J.; Roy, L.D.; Zhou, R.; Grover, P.; Wu, S.T.; Curry, J.M.; Dillon, L.M.; Puri, P.M.; Yazdanifar, M.; Puri, R.; et al. Antibody-Guided In Vivo Imaging for Early Detection of Mammary Gland Tumors. Transl. Oncol. 2016, 9, 295-305. [CrossRef] [PubMed]

23. Zhou, R.; Curry, J.M.; Roy, L.D.; Grover, P.; Haider, J.; Moore, L.J.; Wu, S.T.; Kamesh, A.; Yazdanifar, M.; Ahrens, W.A.; et al. A novel association of neuropilin-1 and MUC1 in pancreatic ductal adenocarcinoma: Role in induction of VEGF signaling and angiogenesis. Oncogene 2016, 35, 5608-5618. [CrossRef] [PubMed]

24. Curry, J.M.; Thompson, K.J.; Rao, S.G.; Besmer, D.M.; Murphy, A.M.; Grdzelishvili, V.Z.; Ahrens, W.A.; McKillop, I.H.; Sindram, D.; Iannitti, D.A.; et al. The use of a novel MUC1 antibody to identify cancer stem cells and circulating MUC1 in mice and patients with pancreatic cancer. J. Surg. Oncol. 2013, 107, 713-722. [CrossRef] [PubMed]

25. Das Roy, L.; Zhou, R.; Moore, L.J.; Dillon, L.M.; Puri, R.; Lyerly, K.; Marks, J.R.; Mukherjee, P. Early detection of breast cancer using a unique tumor specific antibody. J. Clin. Oncol. 2015, 33, abstr-e22153. [CrossRef]

26. Wu, S.-T.; Fowler, A.J.; Garmon, C.B.; Fessler, A.B.; Ogle, J.D.; Grover, K.R.; Allen, B.C.; Williams, C.D.; Zhou, R.; Yazdanifar, M.; et al. Treatment of pancreatic ductal adenocarcinoma with tumor antigen specific-targeted delivery of paclitaxel loaded PLGA nanoparticles. BMC Cancer 2018, 18, 457. [CrossRef] [PubMed]

27. Dréau, D.; Moore, L.J.; Alvarez-Berrios, M.P.; Tarannum, M.; Mukherjee, P.; Vivero-Escoto, J.L. Mucin-1-antibody-conjugated mesoporous silica nanoparticles for selective breast cancer detection in a mucin-1 transgenic murine mouse model. J. Biomed. Nanotechnol. 2016, 12, 2172-2184. [CrossRef] [PubMed]

28. Silvestri, I.; Cattarino, S.; Giantulli, S.; Nazzari, C.; Collalti, G.; Sciarra, A. A perspective of immunotherapy for prostate cancer. Cancers 2016, 8, 64. [CrossRef]

29. Delitto, D.; Wallet, S.M.; Hughes, S.J. Targeting tumor tolerance: A new hope for pancreatic cancer therapy? Pharmacol. Therapeut. 2016, 166, 9-29. [CrossRef]

30. Whilding, L.M.; Parente-Pereira, A.C.; Zabinski, T.; Davies, D.M.; Petrovic, R.M.G.; Kao, Y.V.; Saxena, S.A.; Romain, A.; Costa-Guerra, J.A.; Violette, S.; et al. Targeting of aberrant alphavbeta6 integrin expression in solid tumors using chimeric antigen receptor-engineered T cells. Mol. Ther. 2017, 25, 259-273. [CrossRef]

31. Waterhouse, N.J.; Sutton, V.R.; Sedelies, K.A.; Ciccone, A.; Jenkins, M.; Turner, S.J.; Bird, P.I.; Trapani, J.A. Cytotoxic T lymphocyte-induced killing in the absence of granzymes A and B is unique and distinct from both apoptosis and perforin-dependent lysis. J. Cell Biol. 2006, 173, 133-144. [CrossRef] [PubMed]

32. Chan, A.K.; Lockhart, D.C.; von Bernstorff, W.; Spanjaard, R.A.; Joo, H.G.; Eberlein, T.J.; Goedegebuure, P.S. Soluble MUC1 secreted by human epithelial cancer cells mediates immune suppression by blocking T-cell activation. Int. J. Cancer 1999, 82, 721-726. [CrossRef]

33. Zelenay, S.; van der Veen, A.G.; Bottcher, J.P.; Snelgrove, K.J.; Rogers, N.; Acton, S.E.; Chakravarty, P.; Girotti, M.R.; Marais, R.; Quezada, S.A.; et al. Cyclooxygenase-dependent tumor growth through evasion of immunity. Cell 2015, 162, 1257-1270. [CrossRef] [PubMed]

34. Fujihara, S.; Mori, H.; Kobara, H.; Rafiq, K.; Niki, T.; Hirashima, M.; Masaki, T. Galectin-9 in cancer therapy. Recent Pat. Endocr. Metab. Immune Drug Discov. 2013, 7, 130-137. [CrossRef] [PubMed]

35. Morgan, R.A.; Yang, J.C.; Kitano, M.; Dudley, M.E.; Laurencot, C.M.; Rosenberg, S.A. Case report of a serious adverse event following the administration of $\mathrm{T}$ cells transduced with a chimeric antigen receptor recognizing ERBB2. Mol. Ther. 2010, 18, 843-851. [CrossRef] [PubMed]

36. Zhou, R.; Yazdanifar, M.; Roy, L.D.; Whilding, L.M.; Gavrill, A.; Maher, J.; Mukherjee, P. CAR T cells targeting the tumor MUC1 glycoprotein reduce triple-negative breast cancer growth. Front. Immunol. 2019, 10, 1149. [CrossRef] [PubMed]

37. John, L.B.; Devaud, C.; Duong, C.P.; Yong, C.S.; Beavis, P.A.; Haynes, N.M.; Chow, M.T.; Smyth, M.J.; Kershaw, M.H.; Darcy, P.K. Anti-PD-1 antibody therapy potently enhances the eradication of established tumors by gene-modified T cells. Clin. Cancer Res. 2013, 19, 5636-5646. [CrossRef] 
38. Koyama, S.; Akbay, E.A.; Li, Y.Y.; Herter-Sprie, G.S.; Buczkowski, K.A.; Richards, W.G.; Gandhi, L.; Redig, A.J.; Rodig, S.J.; Asahina, H.; et al. Adaptive resistance to therapeutic PD-1 blockade is associated with upregulation of alternative immune checkpoints. Nat. Commum. 2016, 7, 10501. [CrossRef]

39. Van Baren, N.; Van den Eynde, B.J. Tryptophan-degrading enzymes in tumoral immune resistance. Front. Immunol. 2015, 6, 34. [CrossRef]

40. Pilotte, L.; Larrieu, P.; Stroobant, V.; Colau, D.; Dolusic, E.; Frederick, R.; De Plaen, E.; Uyttenhove, C.; Wouters, J.; Masereel, B.; et al. Reversal of tumoral immune resistance by inhibition of tryptophan 2,3-dioxygenase. Proc. Natl. Acad. Sci. USA 2012, 109, 2497-2502. [CrossRef]

41. Frumento, G.; Rotondo, R.; Tonetti, M.; Damonte, G.; Benatti, U.; Ferrara, G.B. Tryptophan-derived catabolites are responsible for inhibition of $\mathrm{T}$ and natural killer cell proliferation induced by indoleamine 2,3-dioxygenase. J. Exp. Med. 2002, 196, 459-468. [CrossRef] [PubMed]

42. Hwu, P.; Du, M.X.; Lapointe, R.; Do, M.; Taylor, M.W.; Young, H.A. Indoleamine 2,3-dioxygenase production by human dendritic cells results in the inhibition of T cell proliferation. J. Immunol. 2000, 164, 3596-3599. [CrossRef] [PubMed]

43. Terness, P.; Bauer, T.M.; Rose, L.; Dufter, C.; Watzlik, A.; Simon, H.; Opelz, G. Inhibition of allogeneic T cell proliferation by indoleamine 2,3-dioxygenase-expressing dendritic cells: Mediation of suppression by tryptophan metabolites. J. Exp. Med. 2002, 196, 447-457. [CrossRef] [PubMed]

44. Munn, D.H.; Shafizadeh, E.; Attwood, J.T.; Bondarev, I.; Pashine, A.; Mellor, A.L. Inhibition of T cell proliferation by macrophage tryptophan catabolism. J. Exp. Med. 1999, 189, 1363-1372. [CrossRef] [PubMed]

45. Ninomiya, S.; Narala, N.; Huye, L.; Yagyu, S.; Savoldo, B.; Dotti, G.; Heslop, H.E.; Brenner, M.K.; Rooney, C.M.; Ramos, C.A. Tumor indoleamine 2,3-dioxygenase (IDO) inhibits CD19-CAR T cells and is downregulated by lymphodepleting drugs. Blood 2015, 125, 3905-3916. [CrossRef] [PubMed]

46. Thaker, A.I.; Rao, M.S.; Bishnupuri, K.S.; Kerr, T.A.; Foster, L.; Marinshaw, J.M.; Newberry, R.D.; Stenson, W.F.; Ciorba, M.A. IDO1 metabolites activate beta-catenin signaling to promote cancer cell proliferation and colon tumorigenesis in mice. Gastroenterology 2013, 145, 416-425. [CrossRef]

47. Nagahara, K.; Arikawa, T.; Oomizu, S.; Kontani, K.; Nobumoto, A.; Tateno, H.; Watanabe, K.; Niki, T.; Katoh, S.; Miyake, M.; et al. Galectin-9 increases Tim-3+ dendritic cells and CD8+ T cells and enhances antitumor immunity via galectin-9-Tim-3 interactions. J. Immunol. 2008, 181, 7660. [CrossRef]

48. Golden-Mason, L.; McMahan, R.H.; Strong, M.; Reisdorph, R.; Mahaffey, S.; Palmer, B.E.; Cheng, L.; Kulesza, C.; Hirashima, M.; Niki, T.; et al. Galectin-9 functionally impairs natural killer cells in humans and mice. J. Virol. 2013, 87, 4835. [CrossRef]

49. Goncalves Silva, I.; Yasinska, I.M.; Sakhnevych, S.S.; Fiedler, W.; Wellbrock, J.; Bardelli, M.; Varani, L.; Hussain, R.; Siligardi, G.; Ceccone, G.; et al. The Tim-3-galectin-9 secretory pathway is involved in the immune escape of human acute myeloid leukemia cells. EBioMedicine 2017, 22, 44-57. [CrossRef]

50. He, Y.; Cao, J.; Zhao, C.; Li, X.; Zhou, C.; Hirsch, F.R. TIM-3, a promising target for cancer immunotherapy. Onco Targets Ther. 2018, 11, 7005-7009. [CrossRef]

51. Zhu, C.; Anderson, A.C.; Schubart, A.; Xiong, H.; Imitola, J.; Khoury, S.J.; Zheng, X.X.; Strom, T.B.; Kuchroo, V.K. The Tim-3 ligand galectin-9 negatively regulates T helper type 1 immunity. Nat. Immunol. 2005, 6, 1245-1252. [CrossRef] [PubMed]

52. Kang, C.-W.; Dutta, A.; Chang, L.-Y.; Mahalingam, J.; Lin, Y.-C.; Chiang, J.-M.; Hsu, C.-Y.; Huang, C.-T.; $\mathrm{Su}, \mathrm{W} .-\mathrm{T}$; $\mathrm{Chu}, \mathrm{Y} .-\mathrm{Y}$; ; et al. Apoptosis of tumor infiltrating effector TIM-3+CD8+ T cells in colon cancer. Sci. Rep. 2015, 5, 15659. [CrossRef] [PubMed]

53. Gleason, M.K.; Lenvik, T.R.; McCullar, V.; Felices, M.; O’Brien, M.S.; Cooley, S.A.; Verneris, M.R.; Cichocki, F.; Holman, C.J.; Panoskaltsis-Mortari, A.; et al. Tim-3 is an inducible human natural killer cell receptor that enhances interferon gamma production in response to galectin-9. Blood 2012, 119, 3064-3072. [CrossRef] [PubMed]

54. Galore-Haskel, G.; Nemlich, Y.; Greenberg, E.; Ashkenazi, S.; Hakim, M.; Itzhaki, O.; Shoshani, N.; Shapira-Fromer, R.; Ben-Ami, E.; Ofek, E.; et al. A novel immune resistance mechanism of melanoma cells controlled by the ADAR1 enzyme. Oncotarget 2015, 6, 28999-29015. [CrossRef] [PubMed]

55. Ishizuka, J.J.; Manguso, R.T.; Cheruiyot, C.K.; Bi, K.; Panda, A.; Iracheta-Vellve, A.; Miller, B.C.; Du, P.P.; Yates, K.B.; Dubrot, J.; et al. Loss of ADAR1 in tumours overcomes resistance to immune checkpoint blockade. Nature 2019, 565, 43-48. [CrossRef] [PubMed] 
56. Pang, L.Y.; Hurst, E.A.; Argyle, D.J. Cyclooxygenase-2: A role in cancer stem cell survival and repopulation of cancer cells during therapy. Stem Cells Int. 2016, 2016, 2048731. [CrossRef] [PubMed]

57. Kalinski, P. Regulation of immune responses by prostaglandin E2. J. Immunol. 2012, 188, 21. [CrossRef] [PubMed]

58. Sobolewski, C.; Cerella, C.; Dicato, M.; Ghibelli, L.; Diederich, M. The role of cyclooxygenase-2 in cell proliferation and cell death in human malignancies. J. Cell Biol. 2010, 2010. [CrossRef] [PubMed]

59. Koike, N.; Pilon-Thomas, S.; Mule, J.J. Nonmyeloablative chemotherapy followed by T-cell adoptive transfer and dendritic cell-based vaccination results in rejection of established melanoma. J. Immunother. 2008, 31, 402-412. [CrossRef]

60. Dudley, M.E.; Wunderlich, J.R.; Yang, J.C.; Sherry, R.M.; Topalian, S.L.; Restifo, N.P.; Royal, R.E.; Kammula, U.; White, D.E.; Mavroukakis, S.A.; et al. Adoptive cell transfer therapy following non-myeloablative but lymphodepleting chemotherapy for the treatment of patients with refractory metastatic melanoma. J. Clin. Oncol. 2005, 23, 2346-2357. [CrossRef]

(C) 2019 by the authors. Licensee MDPI, Basel, Switzerland. This article is an open access article distributed under the terms and conditions of the Creative Commons Attribution (CC BY) license (http://creativecommons.org/licenses/by/4.0/). 